\title{
APLICACIÓN DE PERSEO DESDE EL ÁREA DE EDUCACIÓN FÍSICA
}

\section{Sánchez, J.}

Diplomado en Educación Física. Universidad de Extremadura. Postgrado en Educación Física y Deportiva. Universidad de Huelva

\section{Javisosa4@hotmail.com}

\section{RESUMEN:}

En la sociedad actual, los efectos de la industrialización y el desarrollo tecnológico han producido un incremento del sedentarismo. En este sentido, hemos de saber que cada día que pasa se acumulan más pruebas de que el sedentarismo y la falta de actividad física influyen de manera relevante en el desarrollo de múltiples enfermedades y que la actividad física tiene efecto tanto preventivo como terapéutico en infinidad de ellas.

Conscientes de ello, los ministerios de Educación y Ciencia y de Sanidad y Consumo, han puesto en marcha diferentes programas $y$ actuaciones encaminadas a prevenir y solucionar este problema. Entre estos programas se encuentra Perseo, creado para prevenir el sobrepeso entre los escolares. Este programa consta de un material curricular a través del cual se pretende concienciar a los alumnos y familias de la importancia de tener una alimentación sana y practicar actividad física de forma regular para gozar de una buena salud.

Por todo ello, en este proyecto se pretende crear una adherencia a la actividad física en niños/as de 10-11 años de un colegio público de la provincia de Huelva a través del área de Educación Física. Para ello, se ha aplicado el Programa Perseo adaptándolo al contexto y realidad del Centro y a las características de nuestros alumnos y Unidad Didáctica. 
Para aplicar este Programa, se ha elaborado una Unidad Didáctica que consta de 8 sesiones, llevadas a cabo a lo largo de los meses de marzo y abril. Esta Unidad Didáctica se ha desarrollado concretamente en el CEIP El Puntal con los alumnos de $5^{\circ}$ de primaria $B$.

A lo largo de las sesiones, nuestros alumnos han ido practicando actividades físicas motivantes donde se trabajaban contenidos relacionados con la actividad física y la salud. Tras cada práctica, se ha hecho una puesta en común a modo de reflexión sobre los aprendizajes y contenidos trabajados, para posteriormente en casa, realizar las actividades curriculares que nos ofrece el Programa Perseo. De este modo se trabajaron los contenidos de forma más teórica, obteniendo unos resultados que nos dieron la oportunidad de analizarlos y sacar unas conclusiones finales sobre nuestro trabajo y validez del Programa Perseo.

Entre los resultados encontrados, podemos decir que el programa Perseo provoca un cambio de actitud en los alumnos, los cuales toman conciencia de la importancia que tiene la actividad física en nuestro día a día para tener un estilo de vida saludable.

PALABRAS CLAVE: Actividad física, salud y obesidad infantil.

\section{INTRODUCCIÓN}

\subsection{JUSTIFICACIÓN}

Los distintos cambios sociales y económicos que han tenido lugar en las últimas décadas se han acompañado de una rápida evolución en los hábitos alimentarios y en los estilos de vida. Como consecuencia de estas circunstancias se han incorporado a la dieta habitual una gran cantidad de productos procesados y refinados con una elevada densidad calórica y se ha reducido el consumo de alimentos ricos en fibra y con alta densidad en micronutrientes. Al mismo tiempo ha disminuido considerablemente el esfuerzo físico realizado en las tareas cotidianas y 
desplazamientos habituales y cada vez se dedica más tiempo a actividades sedentarias, tanto en el trabajo como en el tiempo de ocio que desembocan en problemas graves de salud. Carranza, Garriga y Llinás $(2011,26)$ señalan que "En el llamado primer mundo, en el primer cuarto de siglo XXI, el desarrollo tecnológico y del bienestar y la sociedad de consumo, nos están llevando a situaciones desconocidas hasta ahora y para las que muchas personas no han sido educadas ni están preparadas genéticamente".

Como consecuencia de estas transformaciones la prevalencia de sobrepeso y obesidad ha aumentado de manera alarmante en las últimas décadas, en mayor medida en los grupos socioeconómicos menos favorecidos y especialmente en la población infantil y juvenil, como quedó establecido en las conclusiones del estudio Enkid del año 2000, para configurarse como uno de los principales problemas de salud pública que requiere la puesta en marcha de acciones decididas para revertir esta tendencia.

Tal es el problema que incluso la OMS, citado en Perseo (2012) ha calificado la obesidad como la epidemia del siglo XXI y nos aporta datos alarmantes como que:

- En la Unión Europea más de 400.000 niños y niñas se vuelven obesos cada año.

- En España 4 de cada 10 niños y niñas (42,7\%) de entre 6 y 10 años de edad, tienen sobrepeso. De los cuales 1 es obeso (9.2\%).

La obesidad, aparte de ser un trastorno metabólico en sí mismo, está asociada al desarrollo de multitud de enfermedades ya desde la edad infantil, de ahí la importancia de su prevención.

EI Proyecto PERSEO pretende fomentar hábitos de actividad física en niños/as de edades comprendidas entre los 6 y 10 años desde el área de Educación Física, para prevenir y reducir los problemas de sobrepeso y mejorar así tanto la salud como calidad de vida de los escolares.

Por todo esto, nos pareció realmente interesante la idea de poder aplicar el Programa Perseo en un colegio público de la provincia de Huelva y poder de este modo, comprobar si tiene efectos positivos sobre sus alumnos.

El hecho de poder aplicar el material curricular del Programa Perseo mediante la elaboración de una Unidad Didáctica a través del área de Educación Física, resultaba aún más motivante, demostrando y comprobando la importancia que este área tiene sobre ciertos contenidos del currículum, siendo en muchas ocasiones, la más 
apropiada para el desarrollo y adquisición de los mismos por parte de nuestros alumnos.

Por tanto, los objetivos de este trabajo son los siguientes:

\subsection{OBJETIVOS DEL TRABAJO}

1.- Adaptar el programa Perseo a una UD en Primaria.

2.- Aplicar la adaptación del programa Perseo en un colegio público a través de la asignatura de EF.

3.- Analizar la aplicación de la Unidad Didáctica y el programa Perseo mediante entrevistas, trabajos y cuestionarios de los agentes implicados en el proyecto.

\section{2. ¿CÓMO PODEMOS ORIENTAR EL ÁREA DE ED.FÍSICA PARA QUE TENGA EFECTOS POSITIVOS SOBRE LA SALUD DE NUESTROS ALUMNOS? ¿QUÉ ASPECTOS DEBEMOS TENER EN CUENTA?}

De todo lo descrito anteriormente, podemos sacar algunas conclusiones como que no cabe duda que el principal activo de la Ed. Física es el movimiento y, por tanto, la participación continua del alumnado debe ser requisito indispensable de toda actuación.

Sin embargo, la validez de dicha participación, estará condicionada por el factor de satisfacción, es decir, deberemos proponer actividades que logren que los alumnos disfruten, generando actitudes positivas hacia la actividad física relacionada con la salud. Y donde estas posean una orientación más hacia el proceso, o a las propias connotaciones afectivo-sociales que acompañen a la vivencia de practicarla, que hacia el resultado que se puede obtener a través de ella, como la mejora de la apariencia, la victoria, etc. $Y$ es que los alumnos orientados hacia la tarea crean un mayor desarrollo personal y refuerzan el compromiso hacia la participación en los deportes de vida y salud, es decir, se relacionaría con una persistencia más alta y un menor abandono (Peirón y cols., 1999), citados por Casimiro, Delgado y Águila C. (2005).

Dishman y cols, (1985), citados en Sánchez Bañuelos (1996), demostraron que la decisión inicial de participar en programas de ejercicio físico puede estar motivada en un primer momento por la preocupación por la salud, pero que lo realmente importante para persistir en la práctica de la actividad física y, en su caso, mantener la adherencia a la práctica del ejercicio físico serán los sentimientos de bienestar y de placer asociados a dicha práctica. Del mismo modo, Pérez Samaniego (1999:141) afirma 
que "la actividad física no debería ser calificada de saludable si no produce placer a quien la práctica". Y es que, limitar el espectro de beneficios exclusivamente a los de tipo orgánicos, obviando las enormes posibilidades de sensaciones placenteras y gratificantes que origina el movimiento significa sesgar su enorme potencial, pues para mejorar la salud no se requiere de una práctica excesiva y agotadora, que acabe por destruir la ilusión y decisión inicial de cualquier sujeto a practicar actividad física, y si, en cambio, descubrir sensaciones placenteras que ayuden a dilatar la realización de actividades físico deportivas en el tiempo. En este sentido un aspecto fundamental será partir de los intereses de los alumnos, es decir, conocer aquellas actividades que mas les atraen, para desde ellas planificar nuestra intervención. Por tanto, como destaca Fraile (1996:15) "el programa debe adaptarse a los gustos de los participantes, de forma que se sientan motivados a realizar dicha actividad como parte integrante de su vida diaria".

Por otro lado, Casimiro, Delgado y Águila, (2005) nos aseguran en su libro Actividad física, educación y salud. Que "los juegos y actividades lúdicas son un buen aliado para acercar muchos de los contenidos al alumnado, siempre y cuando estén debidamente organizadas, de tal modo adulteraban su doble finalidad: lograr la satisfacción de los alumnos y presentar, y posibilitar, un contenido concreto de aprendizaje". A estas finalidades las une una delgada línea que obliga al docente a implicarse activamente en las actividades propuestas, para ir encauzando su desarrollo, pues no se puede caer en un mero recreacionismo, donde la experiencia del alumnado se limita a que este se divierta y se lo pase bien. Esta circunstancia no puede pasar desapercibida entre los profesionales de la educación física, y debe primar incluso mucho antes que otros, muchos objetivos aparentemente más genuinos de esta área, puesto que es la llave que posteriormente dará la posibilidad de lograr esos mismos u otros objetivos siempre, claro está, que dicha satisfacción, o disfrute, sea un simple envoltorio que guarde en su interior un claro valor educativo.

Estos mismos autores señalan que, entre otros aspectos, ese carácter educativo debe basarse en propiciar un conocimiento teórico práctico que favorezca su autonomía en el diseño y realización de actividad físico deportiva. Para llevar a cabo este principio de actuación será fundamental promover la participación activa de los alumnos en su propio proceso de aprendizaje, haciendo hincapié en la búsqueda de significado de aquello que hace, y partiendo de contenidos significativos para ello, ya que el aprendizaje se facilitara si este es relevante para los alumnos.

Para lograr que los alumnos adquieran ese conocimiento teórico práctico se deberá dejar de lado, tal y como señala Sánchez Bañuelos (1992:6-7), "el concepto del 
alumno esponja que absorbe de una manera pasiva la sabiduría que emana el profesor".

Adquiere aquí una gran importancia la opinión de algunos autores como Devís y Peiro (2002) y Fraile (1996) que están convencidos de la importancia que posee intercalar momentos de reflexión con la práctica para de este modo, lograr una mejor comprensión.

En este mismo sentido, Casimiro, Delgado y Águila (2005) nos dicen que para dar respuesta a esta cuestión se pueden utilizar recursos como, por ejemplo, fichas, trabajos trípticos, que relacionen la teoría y la práctica y provoque en los alumnos disonancia cognitiva, o el desarrollo de su creatividad. Estos mismos autores señalan que si existe una actuación concreta motivada exclusivamente por las características de la sociedad actual, y ante la que la escuela y los profesionales de la educación física no pueden permanecer impasibles, esta es la de desarrollar en los alumnos una conciencia crítica ante determinados temas que atentan contra la salud individual y pública.

El profesor deberá tener presente que para desarrollar en los alumnos un pensamiento autónomo y una mentalidad crítica, será necesario que de mas importancia a los procesos que a los productos terminados del aprendizaje, por lo que cobrará gran importancia que favorezca las experiencias de reflexión y dialogo, y que escuche y oriente más que imponga De Gregorio, 2002; Devís y Peiro, 2001).

Dado que el tiempo que los niños/as están practicando actividad física en horario escolar es muy pequeño con respecto al total que le dedica niño/a al total la eficacia de las clases de educación física, en la etapa de formación debería medirse por la capacidad que tenga para motivar e interesar al alumno a una práctica regular y voluntaria de actividad física en su tiempo libre, así como conseguir una coherencia interna entre el enfoque teórico de actividad física para la salud y su puesta en práctica real. Esto lleva a tener que hacer compatible una actividad física que permita que el niño disfrute de la misma, pero a la vez que exija un nivel de esfuerzo y dificultad que sea significativo para el alumno y que le permita desarrollar su condición física y su nivel de habilidad motriz (Sánchez Bañuelos, 1996).

Por tanto, la labor del profesional en educación física y deportiva no debe quedar reducida a su actuación en el colegio o escuelas deportivas, sino que debe fomentar, sobre todo, la creación de un hábito de vida activo. Para ello su quehacer ha de ir mas encaminado a enseñar al niño porque, cuando y como debe realizar la actividad físicodeportiva (saber hacer), que la consecución deportivo especifico de rendimientos 
(conseguir hacer), haciendo compatible el disfrute de la misma con un nivel de exigencias significativos para el alumno (Delgado y Tercedor, 1998).

\section{PROGRAMAS DE INTERVENCIÓN DE ACTIVIDAD FÍSICA Y SALUD EN ESPAÑA}

Evidentemente, el principal programa de intervención en el que se basa este trabajo, es el Programa Perseo, que posteriormente pasaremos a explicar y analizar. Pero parece conveniente, tener en cuenta y conocer otros programas de intervención de actividad física y salud llevados a cabo en nuestro país, de modo que podamos ver y entender el amplio abanico de posibilidades que tenemos para proponer diferentes actividades y programas saludables con nuestros/as alumnos/as en particular y con la población en general.

Además del proyecto PERSEO, a nivel estatal, se han planteado también diferentes propuestas de intervención encaminadas a la prevención de la obesidad, como el programa Thao-Salud (2008). Esta iniciativa se basa en el programa EPODE iniciado en Francia en 2004, un programa que se puso en marcha a partir de la experiencia realizada en dos ciudades del Norte de Francia, Fleurbaix y Laventie, en 1992. Aquella experiencia puso de manifiesto que las acciones en las escuelas y en la ciudad tienen un impacto positivo y pueden frenar la progresión de la prevalencia de la obesidad y el sobrepeso en los niños. El Programa EPODE ("Ensemble Prévenons l'Obésité Des Enfants") comenzó en 10 ciudades piloto francesas de la mano de la agencia francesa de comunicación.

Thao-Salud Infantil inició su andadura en 2007 en 5 municipios piloto. Se trata de un programa de promoción de los hábitos saludables en el ámbito municipal. El Programa va dirigido a los niños escolarizados de 3 hasta 12 años, implicando a todos los actores locales en contacto con la población infantil. Desde el año 2010, se ha empezado a desarrollar un programa específico para los niños de 0 a 3 años.

La estrategia del proyecto incluye una primera etapa de información y sensibilización dirigida a los actores locales a través de estrategias de comunicación. En una segunda fase se inicia la intervención en los colegios. Contempla un componente de prevención secundaria dirigido a profesionales sanitarios y familias con niños con exceso de peso. Información Disponible en:

"Niños en movimiento" citado en En movimiento (2012). Es un programa estructurado dirigido a modificar hábitos alimentarios, estilos de vida y aspectos 
emocionales en niños obesos (6-12 años) y sus familias, como parte del plan de tratamiento de estos niños y sus familias desde el ámbito de la consulta especializada. Los resultados muestran una disminución en el IMC, un aumento de la calidad de la dieta mediterránea, y una menor ansiedad. Se observó una capacidad de seguimiento a largo plazo en el 59\% de la población.

Proyecto de investigación Movi, Universidad Castilla la Mancha (2012). Dirigido a evaluar la eficacia de una intervención para promover la actividad física de tiempo libre con el fin de prevenir el sobrepeso/obesidad y otros factores de riesgo cardiovascular en escolares. Los resultados después de dos años de implementación del proyecto en 10 colegios de Cuenca resultaron alentadores con una reducción de la prevalencia de obesidad del $6 \%$ en las niñas y un $2 \%$ en los niños y una mejora sustancial en el perfil lipídico.

Pero sin duda alguna, unas de las propuestas de intervención o programas más conocidos sobre actividad, física, salud y obesidad es la Estrategia Naos, que es en la que se basa el Proyecto Perseo. Pasemos a hablar de ella más detenidamente.

\subsection{ESTRATEGIA NAOS}

En el año 2005 se puso en marcha la Estrategia NAOS (Estrategia para la Nutrición, Actividad Física y Prevención de la Obesidad) desde el Ministerio de Sanidad y Consumo, a través de la Agencia Española de Seguridad Alimentaria y Nutrición (AESAN), con el objetivo de sensibilizar a la población del problema que la obesidad representa para la salud, y de impulsar todas las iniciativas que contribuyan a lograr que los ciudadanos, y especialmente los niños y los jóvenes, adopten hábitos de vida saludables, principalmente a través de una alimentación saludable y de la práctica regular de actividad física.

La Estrategia NAOS pretende servir como plataforma de todas las acciones que ayuden a la consecución de dicho objetivo, integrando los esfuerzos y la participación más amplia posible de todos los componentes de la sociedad, Administraciones Públicas, expertos en el tema, empresas del sector privado, consumidores, y toda la población. De este modo, los ámbitos y los campos de actuación e influencia de la Estrategia NAOS son múltiples: la familia, el entorno escolar, el mundo empresarial y el sistema sanitario.

La Estrategia NAOS ha puesto a España en un lugar destacado entre los países a los que se atribuye un mayor dinamismo al enfrentarse al reto de contrarrestar la 
epidemia de la obesidad, y así lo reconoció la oficina regional europea de la Organización Mundial de la Salud, que en su Conferencia Ministerial celebrada en Estambul en noviembre de 2006, otorgó a la Estrategia NAOS uno de sus premios, por la forma en que aborda la colaboración entre las administraciones públicas y los agentes sociales privados. La Unión Europea también ha hecho el honor reiteradamente de invitar al Ministerio y a la Agencia Española de Seguridad Alimentaría y Nutrición como ponente a sus distintos foros para explicar las experiencias en el desarrollo de la Estrategia.

En Nuestro país, algunos centros educativos han puesto en marcha proyectos de actividad física, alimentación y prevención de la obesidad siguiendo las pautas que marca la estrategia NAOS, la cual otorga un reconocimiento obsequiándoles con un premio a aquellos centros educativos que mejores proyectos presentan.

\subsection{PERSEO}

De entre todos los programas de intervención de actividad física y salud descritos anteriormente, hemos decidido escoger el Programa Perseo para el desarrollo y elaboración de nuestro trabajo, ya que, es sin duda alguna es el que mejor se adapta a los objetivos que perseguimos y el que mejor podemos trabajar desde el área de Educación Física, además de ser el más completo tanto en contenidos como en material curricular.

\section{Principios generales}

Los hábitos alimentarios y comportamientos sedentarios se desarrollan en la infancia y se consolidan durante la adolescencia, siendo luego muy difíciles de modificar. Por eso, la mejor edad para intervenir sobre ambos es durante la enseñanza primaria.

La escuela ofrece innumerables oportunidades para formar sobre hábitos alimentarios saludables y fomentar la práctica regular de actividad física y deporte, constituyendo, por eso, uno de los lugares más eficaces para modificar los estilos de vida de los niños, niñas y adolescentes.

Sin embargo, la experiencia demuestra que los resultados son escasos cuando se actúa únicamente sobre los escolares, sin implicar a sus familias y sin actuar simultáneamente sobre el entorno en el que viven. 
Por ello, el programa comenzó con experiencia piloto incluyendo intervenciones sencillas que fuesen fácilmente realizadas en los distintos centros y en el futuro servir como modelo para actuaciones de mayor envergadura.

\section{¿Qué es el programa Perseo?}

EI Programa Perseo es un programa piloto escolar de referencia para la salud y el ejercicio físico contra la obesidad. Es impulsado por los Ministerios de Sanidad y Consumo y de Educación, Política Social y Deporte junto con las Consejerías de Sanidad y Educación de 6 Comunidades Autónomas (Andalucía, Canarias, Castilla y León, Extremadura, Galicia y Murcia) y dos ciudades Autónomas (Ceuta y Melilla). Su objetivo principal es promover hábitos de vida saludable entre los alumnos, de edades comprendidas entre 6 y 10 años, con una implicación por parte de los familiares y actuando, además, simultáneamente sobre el comedor y el entorno escolar para facilitar la elección de las opciones más sanas.

Dicho programa lleva a cabo una estrategia llamada NAOS, estrategia para la nutrición, la actividad física y la prevención de la obesidad elaborada por el Ministerio de Sanidad y Consumo que tiene como finalidad mejorar los hábitos alimentarios e impulsar la práctica regular de la actividad física de todos los ciudadanos, poniendo especial atención en la prevención durante la etapa infantil. Está demostrada la alta probabilidad de que un niño obeso sea en el futuro un adulto obeso. Dado el carácter multifactorial de la obesidad, el reto que afronta la Estrategia requiere de la participación de todos y de un conjunto de actuaciones sostenidas en el tiempo. Sólo así se conseguirán resultados positivos.

En la elaboración de esta Estrategia han colaborado muy activamente distintos sectores de la sociedad: Administraciones públicas, expertos independientes, empresas relacionadas con el sector de la alimentación y de la actividad física, asociaciones, etc.

\section{Objetivos del Programa Perseo}

\section{Objetivos generales:}

$\checkmark$ Promover la adquisición de hábitos alimentarios saludables y estimular la práctica de actividad física regular entre los escolares, para prevenir la aparición de obesidad y otras enfermedades.

$\checkmark$ Detectar precozmente la obesidad y evitar que progrese con evaluaciones clínicas por profesionales sanitarios de atención primaria. 
$\checkmark$ Sensibilizar a la sociedad en general, y sobre todo al entorno escolar, de la importancia que los educadores tienen en este campo.

$\checkmark$ Crear un entorno escolar que favorezca una alimentación equilibrada y la práctica frecuente de actividad física.

$\checkmark$ Diseñar indicadores sencillos fácilmente evaluables.

\section{Objetivos específicos:}

Distribuir adecuadamente la ingesta alimentaria a lo largo del día, reduciendo el porcentaje de escolares que evitan el desayuno o prescinden de alguna comida.

* Disminuir la ingesta de grasas no saludables y azúcares.

* Aumentar el consumo diario de frutas y verduras.

* Promover el consumo de agua como bebida de elección.

* Promover la práctica habitual de actividad física.

* Reducir el tiempo dedicado la televisión, videojuegos u ordenadores.

\section{¿Dónde actúa Perseo?}

Los ámbitos de actuación son:

Profesorado (Nivel de intervención formativo/informativo)

* $\quad$ Alumnado y sus familiares ( Nivel de intervención cognitivo-conductal)

* Equipos directivos (Nivel de intervención formativo/informativo)

* $\quad$ AMPAS (Nivel de intervención formativo/informativo)

* Personal sanitario (Nivel de intervención formativo/informativo)

* Cafeterías-Comedores escolares.

\section{METODOLOGÍA}

Antes de nada es preciso indicar que el programa Perseo está diseñado para aplicarse durante todo un curso escolar y que nosotros solamente hemos dispuesto de un mes para llevarlo a cabo. Pero pensamos que si en este mes hemos podido observar pequeños cambios en la forma de pensar de nuestros alumnos respecto a esta temática, en un curso completo los resultados pueden resultar muy significativos. 


\subsection{CONTEXTO DE ACTUACIÓN}

El trabajo se ha llevado a cabo en el C.E.I.P El Puntal, colegio público situado en Bellavista. Bellavista es una pedanía del municipio de Aljaraque en la provincia de Huelva, situada en el área metropolitana de la capital a tan sólo $8 \mathrm{~km}$. de ella.

El Colegio de Educación Infantil y Primaria "El Puntal", es un Centro educativo formado, para el curso 2011-2012, por seis unidades de educación infantil y trece de primaria. Así mismo cuentan con un aula de pedagogía terapéutica y una de audición y lenguaje. Entre sus objetivos principales se encuentra hacer de la escuela un centro vital de aprendizaje y de enseñanza; un lugar de convivencia y de enriquecimiento mutuo entre alumnado y adultos.

\subsection{PARTICIPANTES}

Los sujetos con los que hemos trabajado son un grupo de alumnos del $3^{\circ}$ ciclo de Educación Primaria, pertenecientes a este colegio, concretamente con el grupo de 5B. Alumnos de 10-11 años, de clase media-alta, los cuales, pensamos que por el estado Psicoevolutivo por el que están atravesando y por el contexto en el que se encuentran, son los más indicados para alcanzar los Objetivos y Contenidos del trabajo programado.

Algunas Características del curso de 5ำ de Primaria B del CEIP "El Puntal”, de la localidad de Bellavista son las siguientes:

Está formado por 26 alumnos/as. Es un grupo heterogéneo, con diferentes intereses, motivaciones, etc. Todos presentan un nivel muy similar en todos los aspectos psicoevolutivos, a pesar de que los niños tienen facetas más destacables que las niñas y viceversa (aspectos que van parejos al desarrollo de ambos sexos).

Cabe mencionar que por las características del entorno tanto físico como social y económico del centro, los alumnos/as fuera del horario lectivo suelen practicar actividades físicas, tanto en juegos en la calle como en actividades físico-deportivas que se llevan a cabo en diferentes escuelas y organizaciones deportivas. Los alumnos/as del grupo-aula no presentan dificultades o déficit motóricos significativos. Es interesante mencionar que dos alumnas presentan indicios de obesidad, aunque el sobrepeso no es demasiado significativo. 


\subsection{PROCEDIMIENTO}

En nuestro trabajo se aplicó una adaptación del Programa Perseo, con la intención de ver su funcionamiento y comprobar si realmente este programa tiene una aplicación práctica en los CEIP desde el área de Educación Física. Pensamos que, una vez aplicado el programa, y hecho un análisis de los resultados obtenidos, sería interesante intentar difundirlos en un artículo de alguna revista de prestigio que permita a los lectores saber en qué consiste el Programa piloto Perseo, y si realmente puede o no funcionar en los CEIP.

Para ello establecimos varias fases o etapas:

\subsubsection{Fase inicial}

Paso 1: Conocer en profundidad el Programa Perseo. Para ello se realizó una lectura exhaustiva del mismo y se buscó información sobre su funcionamiento y resultados que había tenido en otros colegios.

Paso 2: Conocer el contexto donde se iba a aplicar el programa así como el grupo de alumnos con el que se iba a aplicar la Unidad Didáctica que íbamos a elaborar. En este sentido nos acercamos un día al centro, vimos su entorno, sus instalaciones, recursos materiales y hablamos con el Director y Jefa de estudios, los cuales nos explicaron el funcionamiento del centro, el equipo docente y recursos humanos de los que disponían, así como las características de los posibles grupos con los que podíamos trabajar.

Paso 3: Una vez elegido el grupo de alumnos con los que íbamos a llevar a cabo nuestro trabajo, el siguiente paso fue crear y aplicar un cuestionario inicial donde se pudiese sacar información acerca de los hábitos de actividad física de éstos alumnos, para de este modo, poder orientar la Unidad Didáctica en función de las características y necesidades de nuestros alumnos.

\subsubsection{Fase de elaboración}

Paso 4: Elaboración de la Unidad Didáctica. Una vez conocidos los resultados del cuestionario inicial, planteamos una Unidad Didáctica donde se trabajen los contenidos elegidos. Pensamos que nuestros alumnos no conocen las diferentes posibilidades que hay para practicar actividad física, asociando siempre ésta a los deportes organizados. Por ello, decidimos orientar la Unidad Didáctica a crear una adherencia 
hacia la actividad física saludable, viendo y comprobando el amplio abanico de posibilidades que existe para poder practicarla. Para trabajar estos contenidos y alcanzar los objetivos propuestos, se crean una serie de sesiones que más adelante pasaremos a explicar.

Paso 5: Se readaptan las fichas del programa Perseo a las sesiones y contenidos trabajados en la Unidad Didáctica. Para ello, agrupamos y cambiamos el orden de las fichas de Perseo en función de los contenidos trabajados en cada una de las sesiones. Es importante resaltar que nuestros alumnos hicieron las 13 fichas que propone el programa Perseo y que los contenidos trabajados en las mismas apenas han sufrido ningún cambio.

\subsubsection{Fase de realización}

Paso 6: Se aplica la Unidad Didáctica que hemos elaborado y el material curricular de Perseo previamente adaptado.

Los objetivos principales de la Unidad Didáctica que elaboramos eran los siguientes:

- Crear una adherencia a la práctica de actividad física por parte de nuestros alumnos.

- Conocer e interiorizar los numerosos beneficios que la actividad física produce en nuestro organismo.

- Conocer las diferentes posibilidades que hay para hacer actividad física.

- Motivar a nuestros alumnos para practicar actividad física y reducir las actividades sedentarias como medio fundamental para prevenir la obesidad.

- Buscar la diversión y aplicación práctica de las actividades en su entorno más cercano.

Todos estos objetivos los hemos llevado a cabo a lo largo de 8 sesiones donde hemos trabajado diferentes formas para practicar actividad física. Las sesiones que componen nuestra Unidad Didáctica son siguiendo el mismo orden, las siguientes:

1. Mi forma física saludable. Sesión donde nuestros alumnos fueron pasando por diferentes pruebas o postas para medir su condición física de diferentes Capacidades Físicas Básicas.

2. Juegos para mejorar mi condición física. Diferentes juegos sencillos y divertidos mediante los cuales se pueden trabajar las diferentes Capacidades Físicas Básicas. 
3. ¿Conocéis el Balonmano? Sesión de iniciación al balonmano a través de diferentes juegos predeportivos.

4. ¿A que jugaban nuestros padres y abuelos? Sesión de juegos populares y tradicionales de su zona y Comunidad Autónoma.

5. Nos orientamos en nuestro entorno. Juego de orientación en las instalaciones del colegio con un mapa del mismo.

6 y 7. Las posibilidades de nuestro entorno. Ruta en bicicleta al parque "El pinar de la sorda" con posteriores juegos en ese mismo entorno.

8. ¿Patinamos? Diferentes juegos lúdicos con los patines.

La metodología que hemos seguido en cada una de ellas ha sido la siguiente. Los primeros 8-10 minutos de clase los dedicábamos a explicar en el aula las fichas del programa Perseo correspondientes a esa sesión y a resolver las posibles dudas de las fichas anteriores. Estas fichas se mandaban para casa y las iban adjuntando en un portafolio llamado "Mi cuaderno de Educación Física" que nos entregaron al finalizar la Unidad Didáctica. Después de esta parte teórica, nos dirigíamos a las pistas donde explicábamos qué es lo que íbamos a trabajar en esa sesión y la parte práctica correspondiente. Todas las sesiones se estaban compuestas por tres partes 0 momentos:

1. Momento de encuentro: Saludo inicial, explicación fichas Perseo y objetivos de la sesión.

2. Momento de actividad Motriz: Actividades principales de la parte práctica de la sesión, siempre de una manera progresiva de exigencia a nivel cardiorespiratorio.

3. Momento de Despedida: Juego de vuelta a la calma y reflexiones finales sobre los contenidos trabajados.

\subsubsection{Fase de análisis}

Paso 7: Elaboramos y aplicamos una entrevista para el profesor de Ed. Física y otra para los alumnos. El objetivo principal de estas entrevistas es conocer algunas fortalezas y debilidades tanto de nuestra Unidad Didáctica como del Programa Perseo.

Para ello, nos reunimos con nuestro profesor en una sala del colegio y le explicamos que queremos hacerle una entrevista referente al trabajo que hemos estado desarrollando durante este último mes en el colegio. Una vez que él acepta, 
comenzamos a hacerle las preguntas manteniendo un orden lógico. Toda esta entrevista fue grabada en archivo de audio para su posterior análisis.

En cuanto a la entrevista a nuestros alumnos, como eran muchos, resultaba imposible hacerle una entrevista individual a cada uno de ellos, ya que no disponíamos de tiempo material para hacerlo. Así que decidimos hacer las preguntas en conjunto. Para ello, les explicamos en qué consistía esta actividad y que era una forma de recoger información para nuestro trabajo. Dejamos claro que las contestasen con sinceridad ya que no hacía falta poner el nombre al documento. Así que, cogiendo los 15 minutos iniciales de la clase de Ed. Física, dictamos las preguntas y nuestros alumnos en silencio y de forma individual las fueron contestando en su folio.

Paso 8: Análisis de los datos obtenidos en las entrevistas y en el material curricular de Perseo. Este análisis nos sirve para establecer una valoración global del proyecto y las conclusiones del mismo.

Para el análisis de las fichas de Perseo, pedimos a nuestros alumnos los portafolios donde las tenían archivadas. Posteriormente fuimos cogiendo ficha por ficha y actividad por actividad para recoger toda la información de las mismas. Todos estos datos los fuimos colocando y archivando en cuadros (ver anexo......) para poder realizar un buen análisis de los mismos.

En cuanto a la entrevista al tutor de prácticas utilizamos la técnica DAFO para analizar la información y poder así conocer las posibles fortalezas, debilidades, amenazas y oportunidades tanto de la UUDD como del programa Perseo

En lo que se refiere al cuestionario final de nuestros alumnos, recogimos todas las respuestas que daban a las preguntas establecidas e hicimos un análisis sobre las mismas.

Después de todo esto, nos dispusimos a hacer un análisis de todos los resultados obtenidos, tanto del cuestionario inicial, como del material curricular de Perseo, de las preguntas finales a los alumnos y de la entrevista personal al tutor de Prácticas.

\subsection{INSTRUMENTOS DE EVALUACIÓN}

Los instrumentos que hemos utilizado para evaluar nuestro trabajo son los siguientes: 
- Cuestionario inicial: El cual se lo pasamos a nuestros alumnos antes de comenzar la Unidad Didáctica. Este cuestionario nos sirvió para conocer el nivel de actividad física practicaban nuestros alumnos antes de la aplicación del programa. Consta de 17 preguntas encaminadas a conocer el nivel de actividad física que practican nuestros alumnos y comprobar qué porcentaje de alumnos son activos y qué porcentaje son sedentarios.

- El cuaderno del alumno, donde se refleja todo el trabajo hecho por nuestros alumnos en lo que se refiere a la aplicación práctica de nuestras sesiones con los materiales curriculares del programa Perseo. Mediante este cuaderno, hemos ido comprobando si nuestros alumnos han adquiriendo los contenidos pretendidos con el desarrollo de nuestro trabajo, así como recoger una serie de datos que nos han permitido establecer los resultados obtenidos con el desarrollo de las fichas de Perseo. Estas fichas las pueden observar en el apartado de anexos, punto 8.2. Por otro lado, los cuadernos de los alumnos con todas sus fichas los tenemos archivados y se encuentran a su entera disposición.

- Diario del profesor: donde se han ido redactando todas las percepciones obtenidas en el desarrollo de todas las actividades y sesiones, así como las reflexiones que hacían nuestros alumnos al final de las mismas, que son las que nos indicaban si nuestros alumnos habían adquirido los aprendizajes que se estaban persiguiendo con el desarrollo de las mismas.

- Cuestionario final (entrevista alumnos): El cual lo pasamos al finalizar la Unidad Didáctica y donde se hicieron preguntas relacionadas con los contenidos trabajados en la misma, así como preguntas relacionadas con una evaluación del material curricular de Perseo por parte de nuestro alumnado. Esto nos permitió conocer de primera mano, tanto los aprendizajes que nuestros alumnos habían alcanzado, como las posibles fortalezas y debilidades de nuestra Unidad Didáctica y del Programa Perseo.

Los objetivos que se perseguían con esta entrevista son:

1. Conocer las posibles fortalezas y las debilidades del desarrollo de la Unidad didáctica desde el punto de vista de los alumnos/as.

2. Averiguar si los alumnos/as aprenden cosas haciendo las fichas del programa Perseo. 
3. Saber la opinión de nuestros alumnos respecto a realizar fichas en el área de Educación Física.

4. Averiguar si se cumplen los objetivos en lo que se refiere a los aprendizajes que han adquirido nuestros alumnos con el desarrollo de la UD.

5. Saber si las sesiones elegidas han sido del interés de nuestro alumnado.

Consta de 7 preguntas que respondieron cada uno de nuestros alumnos de forma individual. Estas preguntas son:

1. ¿Qué os ha gustado más?

2. ¿Qué os ha gustado menos?

3. ¿Qué habéis aprendido?

4. ¿Cómo valoráis las sesiones realizadas? ¿Habéis aprendido algo?

5. ¿Qué os han parecido las fichas?

6. ¿Pensáis poner en práctica algunos juegos y actividades vistos en la UUDD con vuestros familiares y amigos?

7. ¿Qué conclusiones o ideas generales sacáis de esta Unidad Didáctica?

- Entrevista final al tutor de prácticas: Que nos permitió conocer algunas fortalezas y debilidades tanto de la Unidad Didáctica como del Programa Perseo utilizando una técnica DAFO para su análisis. Esta entrevista se hizo una vez acabada la UUDD y todas las fichas de Perseo. Para ello, nos reunimos con el tutor de prácticas y le hicimos una serie de preguntas que fueron grabadas en archivo de audio para el posterior análisis de las respuestas.

Los objetivos por los que se hacen la entrevista son:

1. Averiguar si el programa Perseo tiene utilidad en las clases de EF.

2. Identificar todos los aspectos de carácter interno y externos que son necesarios para desarrollar el programa Perseo en las clases de EF.

Las preguntas que componen esta entrevista son las siguientes:

1. ¿Piensas que se han alcanzado los objetivos de la unidad didáctica? 
2. ¿Crees que la metodología utilizada a lo largo de las sesiones ha sido la más adecuada?

3. ¿Piensas que las sesiones que se han elegido para llevar a cabo la unidad didáctica cumplen con las expectativas del programa Perseo?

4. ¿Has podido observar en los alumnos algún cambio con respecto a la motivación para practicar actividad física en su tiempo libre?

5. ¿Qué opinas sobre los materiales curriculares del programa Perseo que hemos ido entregando? ¿Son un complemento a los contenidos trabajados o por el contrario crees que no son necesarios?

6. ¿Cuáles crees que han sido los puntos fuertes o aspectos positivos de mi unidad didáctica? ¿Podrías indicarme algunas propuestas de mejora?

El análisis de DAFO se puede observar en el apartado 5.4.

\section{UNIDAD DIDÁCTICA}

\section{TÍTULO: "NOS MANTENEMOS SANOS CON LA ACTIVIDAD FÍSICA"}

\subsection{PRESENTACIÓN DE LA UNIDAD DIDÁCTICA}

A continuación se muestra la Unidad Didáctica que hemos desarrollado para llevar a cabo nuestro trabajo. Unidad Didáctica que recuerdo está dirigida a un grupo de 26 alumnos de 5을 de primaria (3ำ ciclo), alumnos de 10 y 11 años, de una pedanía de Aljaraque, concretamente Bellavista, situada a $8 \mathrm{~km}$ de la ciudad de Huelva.

Los contenidos más importantes que se van a trabajar en esta Unidad Didáctica están relacionados con la práctica de actividad física como medio para fomentar hábitos y estilos de vida saludables. Para ello, tendremos en cuenta los contenidos y los materiales curriculares que propone el programa piloto Perseo.

He creído oportuno denominar a la unidad didáctica con el nombre de "NOS MANTENEMOS SANOS CON LA ACTIVIDAD FÍSICA", ya que transmite la filosofía que queremos inculcar con estos juegos, alegría por jugar, disfrute, amistad, colaboración, aventura...etc. 
Se desarrollará en los meses de Marzo y Abril del curso escolar, con una duración de 8 sesiones y una temporalización de 2 sesiones por semana (lunes con una duración de 60 minutos y viernes con una duración de 50 minutos).

\subsection{JUSTIFICACIÓN}

Los cambios sociales, laborales y los estilos de vida de la sociedad actual han provocado un aumento del sedentarismo. Esto ha provocado en los últimos años un aumento de la obesidad infantil y otros problemas de salud asociados.

Además de todo esto, parece ser que los niños y niñas han cambiado la forma de divertirse y ocupar su tiempo libre, cambiando actividades activas de años atrás, por actividades sedentarias como jugar al ordenador y videoconsolas en la que no gastan apenas energía.

Pensamos que la escuela en general y el área de Educación Física en particular pueden incidir y cambiar estos malos hábitos de vida tan negativos que afectan de manera grave a la salud de nuestros alumnos. $Y$ lo pensamos por dos motivos fundamentales:

En primer lugar porque la escuela acoge durante una gran cantidad de años a la mayoría de la población infantil y es en estos años cuando más fácil es crear unos buenos hábitos y estilos de vida saludables en nuestros alumnos.

Por otro lado, creemos que el área de Educación Física es fundamental para afrontar y contrarrestar este tipo de problemas por tres razones básicas:

- Porque aporta conocimientos específicos sobre las relaciones entre la actividad física, la condición física y la salud.

- Porque desarrolla las habilidades y destrezas motrices que permitan a niños ser activos.

- Porque fomenta los hábitos de actividad física, contribuyendo a que las personas incorporen la actividad física a su estilo de vida.

\subsection{RELACIÓN CON EL CURRÍCULO OFICIAL}

\subsubsection{RELACIÓN CON LAS COMPETENCIAS BÁSICAS}

Con el desarrollo de esta UD contribuiremos a alcanzar sobretodo la: 
Competencia social y ciudadana. En todas las sesiones ayudando a aprender a convivir, a respetar, a ser solidarios.

Autonomía e iniciativa personal y la competencia para aprender a aprender. En todas las sesiones iniciando a los alumnos a nuevos aprendizajes y haciendo que sean capaces de continuarlo de manera autónoma. Pretendemos que después de la aplicación de nuestra UD, nuestros alumnos tengan más autonomía a la hora de organizar y practicar diferentes actividades físicas.

Competencia en el conocimiento y la interacción con el mundo físico, que recogerá la habilidad para la comprensión de los sucesos, la predicción de las consecuencias y la actividad sobre el estado de salud de las personas y la sostenibilidad medioambiental.

\subsubsection{RELACIÓN CON LOS OBJETIVOS GENERALES DE ETAPA:}

Esta Unidad Didáctica tiene una vinculación directa con:

El objetivo general de etapa “ $k$ " Valorar la higiene y la salud, aceptar el propio cuerpo y el de los otros, respetar las diferencias y utilizar la educación física y el deporte como medios para favorecer el desarrollo personal y social.

\subsubsection{VINCULACIÓN CON LOS OBJETIVOS GENERALES DE EDUCACIÓN} FísICA.

Los principales objetivos con los que se relaciona nuestra Unidad son los siguientes:

1. Conocer y valorar su cuerpo y la actividad física como medio de exploración y disfrute de sus posibilidades motrices, de relación con los demás y como recurso para organizar el tiempo libre.

2. Apreciar la actividad física para el bienestar, manifestando una actitud responsable hacia uno mismo y las demás personas y reconociendo los efectos del ejercicio físico, de la higiene, de la alimentación y de los hábitos posturales sobre la salud.

\subsubsection{RELACIÓN CON LOS BLOQUES DE CONTENIDOS}

Los contenidos que se van a tratar en la Unidad Didáctica de Promoción de la Actividad Física y Condición Física Saludable son, sin duda, contenidos educativos que entroncan con los recogidos dentro del Real Decreto 1513/ 
2006 de enseñanzas mínimas de Educación Primaria (BOE de 8 de Diciembre). Así, la mayor parte de las actividades pretenden que el alumnado desarrolle una actitud positiva hacia la actividad física y obtenga conocimientos útiles sobre las relaciones entre la actividad física y la salud.

Sin embargo, la Unidad Didáctica quiere ir más allá del desarrollo de conocimientos y actitudes y pretende influir en que alumnos y alumnas realicen (o mantengan si ya lo están realizando) unos niveles de actividad física regular de los que pueden derivarse beneficios para su salud. En definitiva, se trata de contribuir en alguna medida a fomentar unos hábitos de actividad física saludable.

De una manera más específica, esta Unidad Didáctica se relaciona principalmente con el bloque de contenidos no $\mathbf{4}$ aunque también se relaciona con el bloque $\mathbf{n} \div 5$.

El bloque 4, Actividad física y salud, está constituido por aquellos conocimientos necesarios para que la actividad física resulte saludable. Además, se incorporan contenidos para la adquisición de hábitos de actividad física a lo largo de la vida, como fuente de bienestar.

Finalmente, el bloque 5, Juegos y deportes, presenta contenidos relativos al juego y a las actividades deportivas entendidos como manifestaciones culturales de la motricidad humana. Independientemente de que el juego pueda ser utilizado como estrategia metodológica, también se hace necesaria su consideración como contenido por su valor antropológico y cultural.

\subsection{DESARROLLO DE LA UNIDAD DIDÁCTICA}

Pasemos antes a ver los elementos curriculares que pretendo trabajar con el desarrollo de la presente Unidad Didáctica.

El desarrollo de esta unidad didáctica facilitará y ayudará a alcanzar los siguientes 4.4.1 OBJETIVOS DIDÁCTICOS:

- Proporcionar alternativas para el ocio mediante la práctica y conocimiento de las diferentes posibilidades para practicar actividades físicas.

- Conocer la relación entre la actividad física y la salud 
- Crear una sensibilización por parte de nuestros alumnos hacia la práctica diaria de actividad física y de los beneficios que ello supone para nuestra salud.

- Motivar a nuestros alumnos para practicar actividad física y reducir las actividades sedentarias como medio fundamental para prevenir la obesidad.

- Buscar una aplicación práctica de las actividades en su entorno más cercano.

\subsubsection{CONTENIDOS}

Hemos trabajado, tal y como hemos mencionado anteriormente, el bloque de ACTIVIDAD FÍSICA Y SALUD, destacando entre otros, los siguientes contenidos:

- Juegos populares y tradicionales, actividades con patines, ruta en bicicleta.

- Balonmano como alternativa a otros deportes más conocidos y practicados.

- Conocimiento de las diferentes CFB.

- Realización de juegos sencillos lúdicos recreativos y de orientación en entornos naturales y cercanos.

- Experimentación de diferentes juegos y test donde se trabaje la condición física asimilando la importancia de ésta para la salud.

- Reconocimiento y valoración de los beneficios de la actividad física en la salud.

- Aprecio del juego y las actividades deportivas como medio de disfrute, de relación y de empleo satisfactorio del tiempo de ocio.

\subsubsection{METODOLOGÍA}

Intentaremos hacer a los alumnos partícipes de su propio proceso de aprendizaje. Para ello, se favorecerá el dinamismo y la curiosidad espontánea, que lleve a los alumnos a explorar, experimentar y ensayar con su cuerpo y sus posibilidades de movimiento, de forma, que sus conocimientos sean el resultado de su experiencia.

Es nuestra intención el uso de una metodología fundamentalmente activa, entendida no sólo como actividad motriz, sino también como un fomento de actitudes de reflexión y análisis del proceso de enseñanza y aprendizaje, que lleve a los alumnos y alumnas a conocer los objetivos que orientan dicho proceso, fomentando su responsabilidad mediante la toma de decisiones. Se procurará que toda tarea tenga pleno significado para el alumno, tanto por la estructura motriz de aquélla como para los intereses y motivaciones de éste. 
Durante todo el proceso, nos serviremos del juego como medio fundamental para desarrollar los objetivos propuestos. Pensamos que el juego es una de las actividades más relevantes en el desarrollo de la persona, que es necesario para el perfeccionamiento y adquisición de habilidades de índole cognitivas, sociales, conductuales, etc. $\mathrm{Y}$ desde el punto de vista psicológico, unos de los aspectos fundamentales que desempeña y que nosotros buscamos con el desarrollo de esta Unidad Didáctica, es que incremente la motivación y la sensación de realizar una acción placentera.

Los autores más relevantes relacionados con esta temática, citados en Sánchez Bañuelos (2003), definen el juego del siguiente modo:

- Para Piaget, el juego es una forma de adaptación inteligente del niño/a al medio, es una actividad no dirigida, de relación con las personas, con los objetos, con el mundo en general.

- Para Vigotsky, la actividad lúdica constituye un motor de desarrollo en la medida en que contribuye a crear continuamente Zonas de Desarrollo Próximo; además establece que el juego tiene una naturaleza social como resultado de la cooperación entre los jugadores que asumen roles complementarios.

- Para Bruner, el juego es una actividad libre y gratuita por excelencia sin otro fin que el juego mismo y la diversión que conlleva.

Froebel, pedagogo alemán (1782-1852), citado en Sánchez Bañuelos (2003), fundador del jardín de infantes y de un método educativo basado en el juego, "los dones", ya reparó en la importancia del juego, afirmando que "los juegos de construcciones tienen una gran virtud formativa, y con ellos, una persona desarrolla la paciencia, la tenacidad, la exactitud, el orden, la previsión, mientras que su fantasía adquiere el más vasto campo de acción y el material propio para sus creaciones y la facultad de concebir y representar, encuentra en ellos un excelente ejercicio".

En nuestras sesiones, predominará la utilización de estrategias no directivas como el descubrimiento guiado y la enseñanza mediante la búsqueda, dejando al niño que explore y practique desde diferentes situaciones. Pensamos que la mejor manera de que el niño aprenda e interiorice conceptos, procedimientos y actitudes de nuestra Unidad Didáctica, es que descubra por sí mismo. Autores como Piaget y 
Vigotsky, citados en Sáncehez Bañuelos (2003), ya hace años que respaldan esta teoría, asegurando que la mejor forma de que el niño aprenda no es transmitiéndoles el conocimiento ya elaborado, sino que lo elaboren por ellos mismos haciendo uso del aprendizaje significativo. Por lo tanto, este tipo de métodos de enseñanza, serán utilizados en la mayoría de las actividades propuestas, como en la sesión de patines, juegos populares, juegos de orientación etc. Aunque es conveniente decir que también utilizaremos en las ocasiones que lo requieran métodos más directivos como el mando directo y la asignación de tareas. Actividades como la ruta en bicicleta, donde hay que dar unas premisas muy claras para prevenir posibles accidentes, algunas actividades de la sesión de balonmano ya que al tratarse de un deporte reglado hay gestos técnicos y normas que requieren de la utilización de estos métodos y la sesión de las pruebas de condición física ya que son tareas cerradas que hay que ejecutarlas correctamente para obtener resultados fiables.

\subsubsection{ATENCIÓN A LA DIVERSIDAD}

El grupo de $4^{\circ}$ de primaria es un grupo heterogéneo, por lo tanto debemos darle a cada niño lo que necesita y tratar de adaptar las actividades a sus posibilidades y limitaciones y sobre todo dando más importancia al proceso que al resultado. Para poder atender a la esta diversidad podemos utilizar varias vías, (priorización de contenidos, actividades diferenciadas, metodologías diversas, agrupamientos flexibles, flexibilización de criterios de evaluación, trabajo de cooperación, desdoblamientos, apoyo individualizado,...etc.); pero la mejor arma para atender a la diversidad de nuestros alumnos y al grupo heterogéneo se centrará principalmente en el trabajo diario a través de un ajuste continuo de las estrategias de enseñanza aprendizaje, que permitan a los alumnos seguir el proceso en función de sus motivaciones, intereses, necesidades, inquietudes y capacidades. Para ello tendremos en cuenta, diferentes formas organizativas del grupo, distintos agrupamientos, adecuación de espacios y materiales, diferentes métodos de enseñanza etc.

\subsubsection{RECURSOS}

Respecto a los materiales, que vamos a utilizar a lo largo de nuestras sesiones podemos destacar aros, diferentes tipos de balones (baloncesto, balonmano, goma- 
espuma etc.), patines con sus correspondientes protecciones (cascos, coderas, rodilleras, etc.), cuerdas, picas, colchonetas, conos, bicicletas, sacos, bolos, paracaídas y diferentes instrumentos para pesar, medir, caja de medición de la flexibilidad,. Respecto a las instalaciones y espacios, utilizaremos el aula, el gimnasio y la pista polideportiva.

En cuanto a los recursos humanos, decir que hemos tenido una coordinación directa con el maestro de Educación Física de este curso, adaptando en la medida de lo posible nuestra Unidad Didáctica a su programación. Además, en todo momento hemos contado con su ayuda y colaboración en el desarrollo de las sesiones.

\subsection{MATERIAL CURRICULAR PERSEO}

Parece necesario, destacar en este punto un apartado importante en nuestro trabajo como es el material curricular que propone el Programa Perseo, en el cual vamos a hacer un breve resumen de los objetivos y las actividades de cada material

Es importante destacar que consta de 13 fichas, las cuales hemos agrupado en nuestras 8 sesiones en función de los contenidos trabajados en las mismas, buscando una semejanza entre los contenidos trabajados en nuestras sesiones y los contenidos de cada una de las fichas del programa Perseo.

Las actividades desarrolladas en cada una de estas fichas, las pueden observar en el Anexo I donde se pueden ver las diferentes fichas tal y como fueron entregados a nuestros alumnos.

\subsection{ESTRUCTURA Y DESARROLLO DE LAS SESIONES}

Todas las sesiones estarán compuestas por tres partes o momentos:

1. Momento de encuentro: Saludo inicial, explicación fichas Perseo y objetivos de la sesión.

2. Momento de actividad Motriz: Actividades principales de la parte práctica de la sesión, siempre de una manera progresiva de exigencia a nivel cardiorrespiratorio. 
3. Momento de Despedida: Juego de vuelta a la calma y reflexiones finales sobre los contenidos trabajados.

\section{SESION 1. TEST DE CONDICIÓN FÍSICA ¿CÓMO NOS ENCONTRAMOS FÍSICAMENTE?}

EI OBJETIVO de esta actividad es que los alumnos y alumnas aprendan cuáles son los componente de la forma física relacionados con la salud, así como a evaluarse en cada uno de ellos comprobando en cuáles se encuentran fuera de las Zonas Saludables de Condición Física.

Pretende que el alumnado conozca y se familiarice desde la enseñanza primaria con los componentes de lo que en la actualidad se considera como la Condición Física Saludable, así como que aprenda a evaluarse con respecto a lo que se ha denominado Zonas de Condición Física Saludable.

\section{JUSTIFICACIÓN}

La evaluación de la condición física dentro de las clases de Educación Física no está exenta de cierta controversia hasta el punto de que a menudo se ha cuestionado su utilidad y su adecuación. Esto es así porque en el pasado con frecuencia se han utilizado las evaluaciones de condición física para establecer la calificación del alumnado o para medir su mejora. Tales planteamientos son inadecuados por que hoy se sabe que las puntuaciones y las mejoras que obtienen niños y niñas en las pruebas de condición física dependen mucho de su capacidad innata y estadio madurativo y muy poco de su adaptación biológica ("entrenabilidad"). Por ello, no tiene mucho sentido utilizarlas en niños y niñas con los objetivos mencionados porque difícilmente miden el progreso, sino su estadio de maduración.

El objetivo de la actividad que se plantea no tiene nada que ver con la perspectiva que acaba de describirse. El objetivo de esta actividad es educativo y no meramente evaluativo. Pretende que el alumnado conozca y se familiarice desde la enseñanza primaria con los componentes de lo que en la actualidad se considera como la Condición Física Saludable, así como que aprenda a evaluarse con respecto a lo que se ha denominado Zonas de Condición Física Saludable. 
La condición física saludable hace referencia a un estado físico caracterizado por la capacidad de realizar las actividades de la vida diaria con vigor y la demostración de rasgos y capacidades que están asociadas con un bajo riesgo de desarrollo prematuro de condiciones y enfermedades hipocinéticas (asociadas a la falta de movimiento). Existen diferentes propuestas sobre cuáles son los componentes que configuran la condición física saludable (véase la primera parte de la guía) pero en la actividad propuesta se consideran básicamente los seis componentes que contempla la Batería FITNESSGRAM.

Estos son de fácil evaluación, adaptados a la población escolar y cuentan con estándares para evaluar la condición física desde el punto de vista de la salud.

Las zonas de condición física saludables son rangos de puntuaciones en las pruebas que evalúan los componentes de la condición física saludable que, en base a evidencias científicas o a criterios de especialistas, se piensa que están relacionados con un mejor estado de salud o con un menor riesgo de padecer determinadas enfermedades. Estos rangos suelen ser bastante amplios, de modo que tienen en cuenta gran variabilidad entre individuos, aunque establecen un umbral por debajo del cual es razonable pensar que la salud puede deteriorarse.

MATERIALES: Tallímetro, báscula, cajón de flexibilidad, metro, colchonetas, espalderas, cronómetro.

\section{MOMENTO DE ENCUENTRO}

\section{Presentación de la unidad didáctica}

Explicamos a los alumnos en qué va a consistir esta nueva Unidad Didáctica así como los objetivos que pretendemos conseguir.

Buenos días, como sabéis soy Javier y voy a llevar a cabo con vosotros una nueva Unidad Didáctica titulada "nos mantenemos sanos con la actividad física" que consta de 8 sesiones.

Con esta Unidad Didáctica pretendemos desarrollar actividades físicas que os resulten motivantes y divertidas para que podáis practicarlas con vuestros amigos fuera del horario escolar. 
El objetivo principal es que conozcáis los principales beneficios que tiene la actividad física y el deporte para la salud y para ello haremos actividades prácticas en las clases de Educación Física que completaremos con actividades para casa donde tendréis que rellenar una serie de fichas que me iréis entregando en vuestro cuaderno.

¿Sabéis si practicar actividad física es saludable?

¿Conocéis algunos beneficios que tiene el ejercicio físico para nuestra salud?

A continuación, explicamos las actividades no 1 y 2 del cuaderno del alumno. Nos aseguramos de que la hayan entendido y les decimos que las tienen que hacer en casa y traerlas hechas el próximo día.

Posteriormente decimos que la sesión de hoy va a consistir en realizar una serie de pruebas de condición física y les explicamos cual va a ser la metodología que vamos a llevar a cabo. Cada uno lleva su ficha y su bolígrafo para apuntar los resultados obtenidos en cada prueba. Para el desarrollo de las mismas nos pondremos en grupos de 5 personas e iremos pasando por todas las postas.

Bien, ahora nos vamos a dirigir a la pista donde vamos a realizar una serie de pruebas que nos den algunas pistas de cómo está nuestro nivel de condición física. Es importante tener claro que los datos que obtengamos no los vamos a evaluar, sino que va a ser una información para nosotros que nos permita saber si nos encontramos bien físicamente.

\section{MOMENTO DE ACTIVIDAD MOTRIZ}

1a Actividad. RESISTENCIA. Los alumnos tendrán que correr alrededor de la pista durante 5 minutos y contar las vueltas que han hecho para anotarlas en su cuaderno.

Nos dirigimos al gimnasio donde tenemos preparadas 5 postas con una prueba en cada una de ellas. Recordamos a nuestros alumnos que tendrán que ponerse en grupos de 5 e ir pasando por las diferentes postas donde tendrán que ir anotando en sus fichas las puntuaciones obtenidas en cada una de las pruebas.

\section{Posta:}

1. Índice de Masa Corporal o IMC (Body Mass Index o BMI) 
Para obtener el Índice de Masa Corporal es necesario medir el peso y la altura del niño o niña. Para ello se utilizará una báscula y un tallímetro.

Ambos instrumentos pueden estar unidos como un único equipo con el que poder medir la talla y el peso a la vez, o pueden encontrarse separados.

Con independencia de cómo se encuentren estos instrumentos, se aconseja que ambas mediciones se tomen a la misma persona antes de pasar a otra para que el proceso sea más eficaz. Para medir el peso y la altura debe realizarse descalzo y con ropa ligera (camiseta y pantalón corto). Es importante la colocación del cuerpo en la medición de la altura. Se debe situar la cabeza del alumno o alumna visualizando una línea imaginaria que iría desde el plano del ojo al conducto auditivo externo (plano de Frankfurt) y que quede paralela con el suelo. Los datos sobre altura se anotarán en centímetros y los de peso en kilos, ambos sin decimales.

El Índice de Masa Corporal (IMC) se calcula aplicando la siguiente fórmula: IMC = Peso (kg) / Altura al cuadrado (m).

\section{2a Posta:}

\section{Prueba de flexión profunda sentado (Back-saver sit \& reach)}

La prueba debe realizarse descalzo. El alumno o alumna se sentará en el suelo, estirará una pierna apoyando toda la planta del pie en la base del cajón. La otra pierna se colocará flexionada y con toda la planta apoyada en el suelo. Cuando el alumno/a esté preparado, realizará una flexión de tronco hacia delante para desplazar la pieza que sirva de marcador con las dos manos juntas tan lejos como sea posible y sin tirones ni rebotes. Deberá mantener durante 1-2 segundos la posición más lejana y anotarla en centímetros sin decimales. El profesor se situará al lado del sujeto y mantendrá su rodilla estirada. Si los dedos de ambas manos no llegan a la misma distancia, se tomará la distancia media entre los dos. Se realizará con la pierna derecha y con la pierna izquierda anotando ambas mediciones.

\section{3a Posta:}

\section{Prueba de flexión de brazos mantenida (Flexed arm hang)}

En la valoración de la fuerza de brazos, el alumno o alumna se sujetará a la barra con ambas manos y con las palmas hacia fuera. La distancia entre las manos no debe ser muy superior a la distancia de los hombros. Será necesaria una silla y la 
ayuda del profesor o profesora para que el alumno se sitúe en la posición inicial con la barbilla por encima de la barra. Desde ese momento, se iniciará la cuenta del tiempo de la prueba. Se debe detener cualquier tipo de movimientos de balanceo que pueda realizar el sujeto, así como evitar colocar la barbilla sobre la barra con el fin de apoyar el peso del cuerpo sobre ella. Se parará el tiempo cuando el alumno o alumna no pueda mantener la posición o cuando la barbilla esté por debajo de la barra. El tiempo de la prueba se anotará en segundos.

\section{4ㅁ Posta:}

\section{Prueba de enrollamiento abdominal (Curl-up)}

Para realizar esta prueba debemos situar al alumno o alumna tumbado boca arriba sobre una colchoneta, con las piernas semi-flexionadas a $140^{\circ}$ y apoyando las plantas en la colchoneta. El compañero, de rodillas, se situará detrás cogiéndole la cabeza con ambas manos. El alumno o alumna evaluado se situará con sus manos y brazos extendidos tocando con las yemas de sus dedos a la altura de la cinta que marca la posición inicial. El tamaño de la cinta debe ser de 7,5 centímetros para edades hasta 9 años y de 11,5 centímetros a partir de los 10 años. La prueba consiste en que el alumno realice el mayor número de abdominales posibles o un máximo de 75. Se cuenta una abdominal correcta sólo cuando:

- Los talones están en contacto con la colchoneta.

- La cabeza vuelve a la posición inicial sobre las manos del compañero.

- Existe una cadencia continúa sin pausas ni periodos de descanso.

- NO se despegan en ningún momento las yemas de los dedos durante su recorrido por la cinta.

La yema de los dedos ha alcanzado el otro lado de la cinta.

El tiempo no es importante, por lo que hay que intentar que las abdominales se realicen bien y de forma suave. Se aconseja una cadencia de 1 abdominal cada 3 segundos, o lo que es lo mismo, 20 abdominales por minuto, que el profesor puede ir marcando.

\section{5asta:}

\section{Prueba de extensión de Tronco (Trunk Lift)}


El alumno o alumna se situará sobre una colchoneta tumbado boca abajo. Con el cuerpo estirado, colocará los brazos extendidos hacia atrás situando las manos bajo los muslos. Se colocará una marca en la colchoneta en la que el alumno tendrá que mantener su mirada durante toda la prueba. Cuando esté preparado, comenzará a subir el tronco suave y progresivamente hasta donde pueda alcanzar (no exceder nunca de 30 centímetros). La medición se realizará con una regla que se situará frente a la altura de la cabeza del alumno o alumna y nunca debajo de su cabeza. La medida se toma en centímetros y sin decimales desde el suelo a la barbilla realizando la ejecución dos veces y eligiendo el mejor resultado.

\section{MOMENTO DE DESPEDIDA}

Una vez realizadas todas las pruebas, sentamos a nuestros alumnos y les explicamos que tienen que poner el nombre a la ficha y entregármela. El próximo día yo las devolveré y en los 5 primeros minutos de clase haremos los cálculos para obtener los acti-consejos.

Hacemos una reflexión final donde entre todos recordamos la importancia de hacer actividad física, qué significa ser activo y sedentario, cuál era el objetivo principal de la Unidad Didáctica, cuál era su nombre etc.

\section{SESIÓN 2. "NOS DIVERTIMOS TRABAJANDO LAS CFB”.}

\section{JUSTIFICACIÓN}

$\mathrm{Ni}$ que decir tiene que el juego es el elemento metodológico principal de la Educación Física en Primaria y por tanto debe ser un recurso utilizado de un modo eficaz.

En esta sesión, pretendemos trabajar las diferentes capacidades físicas básicas (Fuerza, resistencia, velocidad y flexibilidad a través del juego). El objetivo que se persigue es que los alumnos conozcan las CFB, las diferencien y que comprendan que las pueden trabajar divirtiéndose con sus amigos. Por otro lado, les haremos ver la importancia que tiene el estar físicamente para desenvolverse en las diferentes actividades de su vida diaria.

Además, como en la gran mayoría de las sesiones de esta Unidad Didáctica, pretendemos que el juego y la actividad física sean un objetivo en sí mismo, que el niño aprenda a jugar, juegue con todos y se divierta dotándole de los recursos para 
su tiempo libre y de esparcimiento, recursos que pretendemos que sean motrices y sociales primordialmente. En definitiva, queremos que tenga autonomía para jugar.

\section{OBJETIVOS:}

- Disfrutar con la actividad física.

- Dotar a nuestros alumnos de una amplia gama de juegos sencillos y prácticos para que puedan practicarlos en la calle con sus amigos.

- Conocer y diferenciar las CFB y saber de su importancia para tener una buena condición física que nos haga más saludables.

MATERIALES: Conos chinos, balones de baloncesto y soga.

SESIÓN 3. JUEGOS PREDEPORTIVOS DE BALONMANO. ¿CONOCEIS EL BALONMANO?

\section{JUSTIFICACIÓN}

Hemos decidido realizar esta sesión porque pensamos que es importante que los niños/as conozcan diferentes deportes. Después de hablar con su maestro de Educación Física, sabemos que la gran mayoría de estos niños conocen pocos deportes practicando habitualmente los más conocidos como son el fútbol y el baloncesto. Sabemos que la gran mayoría no conocen el balonmano por lo pensamos que si los introducimos en la práctica de una nueva modalidad deportiva de manera lúdica y divertida, podremos despertar su interés por practicar otro tipo de deportes a los habitualmente conocidos.

Por otro lado, hay niños y niñas a los que no les gustan los deportes que todos conocen y practican, o simplemente se aburren practicándolos porque no se les da bien. Si les damos a conocer otros deportes, tendrán más oportunidades de elegir incluso descubrir que se les da bastante bien un deporte que hasta hacía poco no habían practicado por desconocimiento.

\section{OBJETIVOS:}

- Conocer una nueva modalidad deportiva.

- Motivar a los alumnos mediante actividades lúdicas y divertidas que les despierte el interés por practicar nuevos deportes.

MATERIALES: Balones de baloncesto, pelotas de goma espuma, pelotas de plástico, aros y conos. 


\begin{tabular}{|c|c|c|}
\hline SESIÓN 3 & BALONMANO & DESCRIPCIÓN \\
\hline PARTE INICIAL & $\begin{array}{l}\text { EXPLICACIÓN DE LA } \\
\text { SESIÓN } \\
\text { (5 Min) }\end{array}$ & $\begin{array}{l}\text { Explicamos a nuestros alumnos que vamos a realizar } \\
\text { juegos predeportivos relacionados con el balonmano y } \\
\text { preguntamos qué conocen este deporte. Vamos a la pista } \\
\text { Los alumnos se reparten por el espacio y el maestro } \\
\text { lanzará } 5 \text { balones de goma espuma rojos y dos verdes. Los } \\
\text { rojos matan y los verdes te dan la vida. El juego consiste } \\
\text { en intentar dar con el balón rojo al resto de compañeros, } \\
\text { evitando a la vez ser dado por otros compañeros. Y si el } \\
\text { alumno coge un balón verde, pasárselo a un compañero } \\
\text { que esta en el suelo para salvarlo. El maestro podrá ir } \\
\text { quitando o introduciendo balones en función de cómo se } \\
\text { desarrolle el juego. }\end{array}$ \\
\hline $\begin{array}{l}\text { PARTE } \\
\text { PRINCIPAL }\end{array}$ & $\begin{array}{l}\text { EL CORTA PASES: } \\
\text { (6Min) }\end{array}$ & $\begin{array}{l}\text { Hacemos grupos de } 8 \text {, con } 2 \text { en el centro y } 6 \text { en aros que } \\
\text { están dispuestos en círculo. Éstos últimos con un balón de } \\
\text { baloncesto Ahora los del centro son uno atacante y otro } \\
\text { defensor. El atacante debe recibir pases de los de fuera y } \\
\text { el del centro debe interceptarlos (los de fuera se pueden } \\
\text { pasar el balón entre ellos hasta encontrar el momento } \\
\text { preciso del pase). Si se consigue un pase se contabiliza y } \\
\text { se devuelve la pelota al círculo para continuar igual. A } \\
\text { quien corten el pase pasa a ser defensor, el defensor a } \\
\text { atacante y el atacante pasa al círculo. } \\
\text { Variantes: Los de fuera tienen que dar } 3 \text { pases como } \\
\text { mínimo antes de pasar al del centro. } \\
\text { Meter dos defensores. }\end{array}$ \\
\hline & $\begin{array}{l}\text { DEFENDER EL } \\
\text { CASTILLO: ( } 6 \text { Min) }\end{array}$ & $\begin{array}{l}\text { Dentro de una zona determinada y reducida (círculo o } \\
\text { cuadrado...) colocamos dentro un aro grande y dentro de } \\
\text { éste un cono. Con la misma disposición que en el juego } \\
\text { anterior, uno actuará de defensor del cono (castillo), } \\
\text { mientras que el resto de jugadores, que se habrán dispuesto } \\
\text { en círculo grande alrededor del cono, se empezarán a dar } \\
\text { pases para intentar en un momento determinado lanzar y } \\
\text { derribar el cono sacándolo fuera del aro. El del centro no } \\
\text { puede pisar en ningún momento dentro de la zona que } \\
\text { marca el aro. } \\
\text { El atacante que intente derribar el castillo y no lo consiga, } \\
\text { pasará a ser defensor del mismo y el que antes era defensor } \\
\text { ocupará su lugar de atacante. } \\
\text { Variantes: } 2,3 \text { defensores. }\end{array}$ \\
\hline & $\begin{array}{c}\text { TIROS A PORTERÍA } \\
\text { (8 Min ) }\end{array}$ & $\begin{array}{l}\text { Con } 3 \text { aros y desde diferentes posiciones. Los tres aros los } \\
\text { colocamos para que nuestros alumnos practiquen los pasos } \\
\text { del balonmano con tiros a portería. }\end{array}$ \\
\hline \multirow{4}{*}{ PARTE FINAL } & BALÓN TORRE:( 15 ) & \multirow{2}{*}{$\begin{array}{l}\text { Se forman dos equipos separados por los dos campos de } \\
\text { la cancha de balonmano. El juego consiste en ir pasándose } \\
\text { el balón entre los miembros del equipo al menos } 10 \text { veces } \\
\text { y luego intentar meter el balón en un aro colgado de la } \\
\text { portería. } \\
\text { No se podrá correr con el balón, y no se puede agarrar ni } \\
\text { quitar el balón de las manos. Cuando el equipo que } \\
\text { defiende intercepte el balón, éstos pasarán a atacar. }\end{array}$} \\
\hline & & \\
\hline & & \multirow{2}{*}{ 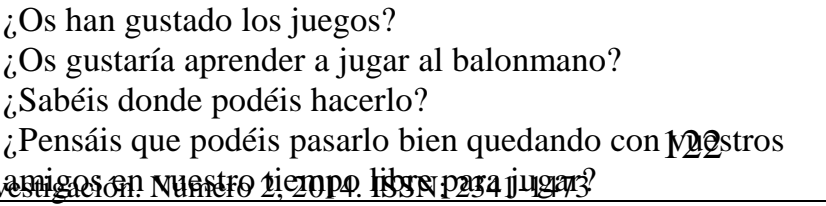 } \\
\hline & & \\
\hline
\end{tabular}




\section{SESIÓN 4. JUEGOS POPULARES Y TRADICIONALES ¿A QUE JUGABAN NUESTROS PADRES Y ABUELOS?}

\section{JUSTIFICACIÓN}

Ni que decir tiene que el juego es el elemento metodológico principal de la Educación Física en Primaria y por tanto debe ser un recurso utilizado de un modo eficaz.

En esta sesión, pretendemos que el juego sea un objetivo en sí mismo, que el niño aprenda a jugar, juegue con todos y se divierta dotándole de los recursos para su tiempo libre y de esparcimiento, recursos que pretendemos que sean motrices y sociales primordialmente. En definitiva, queremos que tenga autonomía para jugar. No hace mucho tiempo, nuestros padres y abuelos se pasaban las tardes jugando en las calles, patios y parques de nuestros pueblos y ciudades. Hoy en día, nuestros más pequeños han cambiado estos juegos por los juegos del ordenador o la televisión con los consiguientes problemas de salud que este sedentarismo ocasiona. Por ello, con esta sesión no solamente buscamos que nuestros alumnos recuperen parte del patrimonio cultural con una serie de juegos que se están perdiendo sino también dotarlo de una serie de recursos que les permitan divertirse y practicar actividad física extrapolándolos a los espacios (Parques y recreos) comunes en los que pueden desenvolverse nuestros alumnos. En conclusión, queremos que nuestros alumnos salgan a jugar a la calle con sus amigos en su tiempo libre.

\section{OBJETIVOS:}

- Disfrutar con la actividad física.

- Practicar juegos populares y/o tradicionales propios de la zona.

- Transmitir la herencia motriz para que se perpetúe.

- Proporcionar alternativas para el ocio a través de elementos culturales como el juego

MATERIALES: Conos, un balón de goma espuma y un pañuelo

Para el desarrollo de esta sesión vamos a tener en cuenta los juegos populares y tradicionales que nuestros alumnos nos han propuesto mediante una investigación hecha a través de preguntas a sus padres y abuelos. 
Por si acaso, nosotros tendremos preparados una serie de juegos para utilizarlos en cualquier momento de la sesión si hace falta tiempo o si fallan algunos de los juegos propuestos ya porque no funcionen o porque no podamos adaptarlos a nuestro contexto.

\section{SESIÓN № 5 “NOS ORIENTAMOS EN NUESTRO ENTORNO” JUSTIFICACIÓN}

Pensamos que los juegos de orientación son actividades donde nuestros alumnos aprenden a orientarse en diferentes entornos, cooperar con los compañeros para conseguir fines comunes y que a la vez disfrutan participando en ellas.

Al ser una actividad que suele resultar bastante motivante y divertida para ellos, les suele enganchar, animándolos a asistir a jornadas y campamentos donde se lleven a cabo este tipo de actividades. Con lo cual estaríamos consiguiendo o persiguiendo unos de los objetivos principales de nuestra Unidad Didáctica, como es crear una adherencia a la práctica de actividad física.

Para la explicación de cómo se va a llevar a cabo esta sesión, hemos creído adecuado hacer una breve descripción de la misma, ya que al contrario que en sesiones anteriores, no se hacen diferentes actividades las cuales tengamos que explicar de manera individual.

Esta sesión consiste en hacer varios equipos a cada uno de los cuales se le asigna un color diferente. Con el mismo número de mapas del colegio que equipos, se ocultan las pistas y se marcan en el mapa del colegio con el color del equipo a quien le corresponda ese mapa.

Cada una de las pistas será una palabra. En total son 10 palabras (pistas) que formarán una frase final. Cuando los equipos encuentren todas las palabras, tendrán que formar una frase que estará relacionado con hábitos y estilos de vida saludable. Gana el equipo que consiga antes formular la frase correctamente.

Posteriormente, se explica el juego a los alumnos. Se les da 3 normas fundamentales:

1․ Hay que encontrar las pistas en el orden que marca el mapa. Es decir, primero la $n^{\circ} 1$, luego la $n^{\circ} 2$ etc.

$2^{\underline{a}}$ No se pueden tocar las pistas de los otros equipos. 
3를 Debemos de ir todos juntos agarrando la cuerda.

\section{FRASES:}

1. Practica actividad física tu cuerpo y tu mente te lo agradecerán.

2. Debemos practicar al menos 30 minutos de actividad física cada día

3. Las actividades sedentarias son aquellas en las que no gastas energía como ver la TV

4. No debes dedicar más de dos horas al día a actividades sedentarias como jugar al ordenador.

5. Para mantenerme sano debo combinar la actividad física con una alimentación saludable.

6. Ser activo me permite sentirme bien conmigo mismo y con todas las personas que me rodean.

\section{OBJETIVOS:}

- Practicar actividades en el medio natural próximo.

- Desarrollar habilidades básicas en entornos cercanos.

- Dar a conocer los juegos de orientación a nuestros alumnos para que se animen a practicarlos en campamentos, jornadas deportivas etc.

- Utilizar un plano del patio para orientarse y localizar objetos.

MATERIALES: Cuerdas, pañuelos de diferentes colores, mapas del colegio hechos por nosotros mismos, ceras de colores, papel, cinta adhesiva.

\section{SESIÓN 6 Y 7. RUTA EN BICICLETA Y ACTIVIDADES EN ENTORNO} NATURAL Y CERCANO.

La sesión 6 y 7 la hicimos conjuntamente al contar con una mañana entera para poder hacer actividades con nuestros alumnos. Pensamos que era apropiado hacer la ruta en bicicleta con posteriores actividades en el entorno natural, ya que los alumnos podrían comprobar lo divertido que puede resultar hacer una excursión en bici y luego aprovechar para jugar con amigos y familiares en el entorno natural hacia el que nos hemos dirigido.

\section{JUSTIFICACIÓN}

La finalidad que perseguimos con la presente sesión es la utilización de la bicicleta como medio para fomentar la actividad física, el ejercicio físico y la 
actividad lúdica, en contra del sedentarismo y la obesidad infantil, fomentando el uso de la bicicleta como medio de transporte en cuanto a la alternativa de la utilización del coche en trayectos cortos, manteniéndose así más activos y quemando más Calorías.

Para ello, fomentaremos la participación de los familiares ya que es un buen método para que los padres e hijos compartan aficiones pudiendo hacer rutas en bicicleta en su tiempo libre.

\section{OBJETIVOS:}

- Utilizar la bicicleta como medio de transporte al Centro Escolar.

- Fomentar el uso de la bicicleta en pequeños desplazamientos en la localidad y en el tiempo libre y de ocio de forma segura y adecuada

- Reducir el porcentaje de obesidad infantil debido al sedentarismo en los tiempos libres y de ocio.

- Practicar diferentes actividades lúdicas en el entorno natural.

- Conocer entornos cercanos en los que poder practicar juegos y actividad física.

MATERIALES: Bicicletas, cascos, merienda, gorra, Lona grande donde hemos dibujado el juego de la oca, dados y fichas.

\section{SESIÓN 8. "JUGAMOS CON NUESTROS PATINES" \\ JUSTIFICACIÓN}

Pensamos que los patines son materiales habitualmente nuestros más pequeños no suelen utilizar o demandarlos como regalos. Sin embargo, nos consta que una vez que aprenden a patinar, son juguetes de los que no se despegan y de los que están deseando coger por las oportunidades de diversión que nos ofrecen.

Por ello, hemos decidido introducir una sesión con materiales activos y atractivos como son los patines, monopatines y sketch, que muchos de nuestros alumnos tienen en casa pero que no los utilizan por miedo o porque simplemente nadie les ha animado a hacerlo.

Aprovechando que su profesor de Educación Física ya ha dado alguna sesión de educación vial con patines, y que la gran mayoría de nuestros alumnos disponen de ellos y saben utilizarlos conociendo las principales normas de 
seguridad, hemos introducido una sesión con estos materiales de ruedas donde vamos a trabajar una serie de contenidos a través de juegos.

Pretendemos que nuestros alumnos se diviertan y se motiven para continuar patinando fuera del horario escolar. Si conseguimos esto, seguro que muchos de nuestros alumnos decidirán salir más días a patinar a la calle y que los alumnos que no tienen patines, pedirán a sus padres que les compren uno y que les enseñen a patinar. Por lo que habremos conseguido unos de los objetivos principales de esta UD, hacer que nuestros alumnos sean más activos en su vida diaria.

\section{OBJETIVOS:}

- Disfrutar con la actividad física.

- Practicar juegos populares y/o tradicionales propios de la zona.

- Transmitir la herencia motriz para que se perpetúe.

- Proporcionar alternativas para el ocio a través de elementos culturales como el juego

MATERIALES: Patines, monopatines, sketch, rodilleras, coderas, cascos, conos, envases de yogures y balones de baloncesto.

\subsection{EVALUACIÓN}

En cuanto a la evaluación, tendremos siempre como referente los objetivos didácticos de la Unidad. Será una evaluación continua y participativa. Respecto a ¿qué evaluar?

- Reconoce e interioriza la relación entre la actividad física y la salud.

- Valora la importancia de la actividad física como medio para tener un estilo de vida saludable

- Identifica las diferentes posibilidades existentes para practicar actividad física.

- Asimila los perjuicios de las actividades sedentarias en relación con la salud.

- Se divierte participando en las diferentes actividades propuestas interactuando con sus compañeros.

Respecto al ¿cuándo y cómo evaluar?

\section{En la evaluación del Alumno}

Lo haremos principalmente mediante: 
- La observación directa, ya que durante todas las sesiones, tanto mi tutor de prácticas como yo, íbamos observando la respuestas que daban nuestros alumnos a las actividades y objetivos planteados en las diferentes sesiones.

- El cuaderno del alumno, donde se refleja todo el trabajo hecho por nuestros alumnos en lo que se refiere a la aplicación práctica de nuestras sesiones con los materiales curriculares del programa Perseo. Mediante este cuaderno, iremos comprobando si nuestros alumnos van adquiriendo contenidos sobre todo a nivel conceptual.

- Las reflexiones finales de nuestros alumnos al finalizar las sesiones y el posterior diario del profesor, donde se han ido redactando todas las percepciones obtenidas en el desarrollo de todas las actividades y sesiones, así como las reflexiones que hacían nuestros alumnos al final de las mismas, que son las que nos indicaban si nuestros alumnos habían adquirido los aprendizajes que se estaban persiguiendo con el desarrollo de las mismas.

\section{En la evaluación del Profesor y la Unidad Didáctica}

Mediante las preguntas hechas a nuestros alumnos al final de la Unidad Didáctica que nos permitirán una valoración de la misma y mediante la entrevista hecha al tutor de prácticas donde nos ha permitido obtener información sobre las debilidades y fortalezas de la misma.

Por otro lado el profesor tendría que rellenar una ficha de varios Ítems haciendo una función de autoevaluación.

\section{ANALÍSIS DE LOS RESULTADOS}

En este apartado hemos tratado de hacer un análisis de los resultados finales del Trabajo que hemos llevado a cabo.

Se incluyen cuadros donde se recoge información tanto de los cuestionarios iniciales y finales, como de las fichas hechas por los alumnos correspondientes al programa Perseo. Por último se recoge un DAFO hecho a partir de la entrevista hecha a mi tutor de prácticas, donde tratamos de valorar las fortalezas y debilidades de la Unidad Didáctica llevada a cabo en el CEIP, la cual recuerdo que trataba de aplicar el programa Perseo mediantes clases prácticas y teóricas desde el área de Educación Física. 


\subsection{CUESTIONARIO INICIAL}

En el análisis del cuestionario que se les pasó a los alumnos el primer día de clase, podemos observar cómo un $98 \%$ de los alumnos asegura que le gusta y practica algún tipo de actividad física y el $100 \%$ dice participar activamente en las clases de Educación Física. Estos datos nos dicen claramente que a casi el 100\% de los alumnos que conforman esta clase les gusta o se sienten atraídos por la actividad física.

Sin embargo, solamente el $15.40 \%$ de los niños participa en alguna actividad extraescolar de su colegio, lo que nos lleva a pensar que no se ofertan o que simplemente no se apuntan o no se sienten atraídos por ellas por diferentes motivos. Aunque en una pregunta posterior, el $66.66 \%$ aseguran participar en las actividades deportivas que su centro organiza fuera y dentro de él, por lo que podemos suponer que el CEIP organiza diferentes actividades complementarias y extraescolares que tienen que ver con la práctica de actividad física

De este $98 \%$ del alumnado que practica y le gusta diferentes actividades físicas, solamente un $52 \%$ lo hace con algún club o escuela deportiva, por lo que entendemos que son autosuficientes en las práctica de actividad física en su tiempo libre y que muchos de ellos practican actividades físicas que no tienen por qué ser de algún deporte en concreto.

En lo que respecta a las actividades físicas no organizadas y del día a día como las tareas del hogar, ir andando al colegio, juegos en la calle etc. Un $86.5 \%$ de los niños aseguran realizarla. Si a esto le añadimos que un $86.4 \%$ asegura que si tiene tiempo libre elige actividades activas, como jugar con los amigos antes que ciertos tipos de actividades sedentarias como ver la TV o jugar al ordenador, podemos observar que estamos en un porcentaje bastante alto, el cual nos incita a pensar que nos encontramos ante un grupo de alumnos bastante activo.

Esto puede ser debido a la motivación que los padres les trasladan, ya que un $92 \%$ del total del alumnado dice que sus padres les animan a practicar algún tipo de actividad física y un $88.5 \%$ dice tener diferentes tipos de material activo en sus casas. Si la mayoría de los regalos y compras que se le hacen a los niños son por parte de los padres, es evidente, que en este sentido, son los principales responsables de que sus hijos practiquen algún tipo de actividad física impulsados por el tipo de regalos que les hacen.

Ante la pregunta de si ¿Crees que es suficiente el deporte que practicas? Un 69. $20 \%$ dice que sí, frente a un 11.50 que es consciente de que no y un 10.20 que dice no 
saberlo. Porcentajes sin ningún rigor científico, ya que nuestros alumnos no pueden compararlo ni comprobarlo en ninguna escala de valores y que podrían cambiar después de hacer entender a nuestros alumnos cuánto tiempo deben practicar actividad física para su edad, mediante las reflexiones durante las sesiones y el material curricular del Programa Perseo.

\subsection{CUADERNO DEL ALUMNO. FICHAS PERSEO}

Las fichas tal y como se las entregamos a nuestros alumnos se pueden consultar en el apartado de anexos, punto 8.2 .Los datos recogidos encada una de estas actividades y de cada uno de nuestros alumnos/as, se pueden observar en el punto 8.3.

\subsubsection{ACTIVIDADES}

\section{ACTIVIDAD 1: ¿ACTIVO O SEDENTARIO? ¿ACTIVA O SEDENTARIA? ¿CÓMO SOY} YO?

El objetivo de esta actividad es que los alumnos y alumnas evalúen sus niveles de actividad física habitual y sus hábitos sedentarios. Para ello se les pide que se autoevalúen tanto respecto a su nivel de actividad física diaria como respecto al tiempo que utilizan a diario en actividades de ocio sedentarias, comparándolos con determinados criterios establecidos.

\section{Análisis de los datos}

En el análisis de esta primera actividad podemos comprobar que 15 de los 22 alumnos que la han realizado (68.18\%), se encuentran dentro de la zona verde del semáforo de la actividad física, es decir, practican bastante actividad física y están dentro de los parámetros planteados, 6 alumnos/as $(27,27 \%$ del total) se encuentran en la zona naranja, por lo que se encuentran en el límite y necesitarían practicar más actividad física para estar saludables y un solo alumno (4.54\%) se encuentra en la luz roja, lo que quiere decir que está por debajo del límite recomendado y que debería reducir sus actividades sedentarias.

\section{ACTIVIDAD 2: ¿ES ACTIVA MAMÁ? ¿ES ACTIVO PAPÁ?}

El objetivo de esta actividad es complementario al de la Actividad 1. Se trata de que el escolar pregunte a su madre y a su padre sobre las actividades físicas que realizan habitualmente y sobre las que le gustaría hacer si pudieran. Después, deben comparar la frecuencia con que ellos realizan actividad física con las recomendaciones existentes para adultos. 


\section{Análisis de los datos}

El análisis de esta actividad nos permite conocer la cantidad de actividad física que practican los padres y madres de nuestros alumnos. En lo que respecta a los padres, 12 , un $57 \%$ del total, se encuentran en la zona verde del semáforo, es decir, están dentro de los parámetros de actividad física recomendados para su edad. En la zona naranja, la cual nos indica que habría que aumentar la práctica de actividad física, se encuentran 6 padres, que representan un 28. 5\% del total y por último, solamente 3 padres (14\%) se encuentran en la zona roja del semáforo, zona que nos indica que estos padres no practican la actividad física necesaria que les produzca beneficios en su salud.

En cuanto a la madres, 9 (43\%) se encuentran en la zona Verde, 11 se encuentran en la zona Naranja (52\%) y solamente 1 se encuentra en la zona Roja (5\%).

A simple vista podemos observar como las madres de nuestros alumnos/as practican una cantidad menor de actividad física que los padres de los mismos, hecho que no afecta a sus hijos/as en el sentido de que las niñas no practiquen actividad física porque sus madres no la practiquen lo suficiente, ya que el $80 \%$ de nuestros alumnos son chicas y como hemos podido comprobar tanto en el cuestionario inicial como en la actividad anterior, son un grupo de alumnos/as por lo general bastante activos.

Si hacemos un porcentaje conjunto ente padres y madres, un $54.76 \%$, es decir, más de la mitad, practican mucha actividad física, un $40.47 \%$ Son bastante activos pero no lo suficiente y solamente un $5 \%$ son demasiado sedentarios.

Parámetros que se asemejan mucho a los parámetros hallados en la actividad 1, lo que nos indica que de padres activos suelen salir hijos activos, y que por el contrario, si los padres son sedentarios, los hijos también lo serán.

\section{ACTIVIDAD 3: LA FORMA FÍSICA SALUDABLE.}

El objetivo de esta actividad es que los alumnos y alumnas aprendan cuáles son los componentes de la forma física relacionados con la salud, así como a evaluarse en cada uno de ellos comprobando en cuáles se encuentran fuera de las Zonas Saludables de Condición Física.

\section{Análisis de los datos}

La interpretación de los datos se recoge en la explicación del desarrollo de la Actividad 4. Allí, se propone la realización de una interpretación conjunta de los resultados 
obtenidos en las actividades 1 y 3 , que permitan establecer un "Perfil" en base al cual proporcionar un consejo individual (ACTICONSEJO)

A modo general y tras una observación de los resultados en cada una de las pruebas, podemos decir que nuestros alumnos necesitan mejorar en flexibilidad y fuerza de brazos.

En las demás Capacidades Físicas Básicas, como son la Resistencia, la Fuerza de Tronco y la Fuerza abdominal, la inmensa mayoría de nuestros alumnos, casi un $90 \%$, se encuentran dentro de los índices recomendados para su edad. Ocurre lo mismo en el IMC, aunque aquí se reduce el porcentaje a un $80 \%$.

\section{ACTIVIDAD 4. ACTICONSEJOS PARA ESTE CURSO.}

El objetivo de esta actividad es valorar de forma conjunta los resultados obtenidos en el activómetro y los resultados de las pruebas de condición física saludable para trazar un perfil de cada alumno o alumna y proporcionarle un consejo individual con relación a sus hábitos de actividad física, así como decidir si es conveniente informar a la familia sobre alguna cuestión específica

\section{Análisis de los datos}

Mediante el presente análisis, podemos comprobar que 18 de los 22 niños un $82 \%$ del total, están dentro de los parámetros recomendados de Condición Física para su edad, mientras que solamente un $18 \%$ se encuentran por debajo de estos parámetros recomendados pero se encuentran en buen estado de forma, debiendo mejorar en algunas Capacidades Físicas Básicas.

Datos que se corresponden con los niveles de actividad física detectados en este grupo de alumnos en actividades anteriores.

\section{ACTIVIDAD 5: ¿POR QUÉ ES BUENA LA ACTIVIDAD FÍSICA?}

El objetivo de esta actividad es hacer conscientes a los alumnos y alumnas de los beneficios de la actividad física sobre la salud. Se presentarán beneficios físicos y otros beneficios que la actividad física produce en la salud desde una idea de salud integral que engloba la salud física, psicológica y social.

\section{Análisis de los datos}

Para el análisis de la siguiente actividad, vamos a dividir las tareas en dos partes. En una primera parte, nuestros alumnos tenían que rellenar una serie de huecos en 7 frases acompañadas de dibujos, donde tenían que completarlas con una serie de 
beneficios de la actividad física como, me veo bien, duermo bien, etc. Se trata de que los alumnos tomen conciencia de la multitud de beneficios que nos ofrece la actividad física. Una actividad relativamente fácil donde 17 alumnos de los 22, han contestado correctamente al $100 \%$ de las preguntas. Entre los 5 alumnos restantes, 3 de ellos han acertado las preguntas por encima del $80 \%$, por lo que podemos deducir que nuestros alumnos comprendieron e interiorizaron bastante bien esta actividad.

En una segunda parte, debían de poner 5 beneficios a nivel anatómico, es decir, beneficios en los huesos, músculos, articulaciones etc. En esta actividad tuvieron bastantes problemas, pues no eran conscientes de estos beneficios. Al explicar la actividad la primera vez, les recomendé que preguntaran a su maestra de conocimiento del medio, pero poco después comprobé que no lo habían hecho, pues a mitad de la Unidad Didáctica pedí todos los cuadernos para revisarlos y comprobar que se estaban entendiendo las tareas. Por ello, volví a explicar la actividad en clase, resolviendo las dudas y dando pistas, por lo que muchos alumnos la hicieron bastante bien posteriormente, aunque como podemos observar en la tabla de arriba, otros muchos siguieron sin entenderla.

Solamente 2 alumnos de los 21 que hicieron la actividad, tienen el 100\% de las respuestas correctas, 8 están en el $50 \%$ y sólo 2 están por encima del $50 \%$.

\section{ACTIVIDAD 6 ¿ME GUSTA LA ACTIVIDAD FÍSICA?}

El objetivo de esta actividad es que alumnos y alumnas se cuestionen si realmente les gusta o no les gusta la actividad física y por qué. Mediante esta actividad se podrá conocer porqué les gusta la actividad física o por qué no, y si el alumno o alumna presenta una actitud positiva o negativa hacia la práctica de la actividad física.

\section{Análisis de los datos}

Después de analizar detenidamente los datos obtenidos en esta actividad, podemos decir que las principales razones por las que a nuestros alumnos les gusta la actividad física son porque se divierten, porque es beneficiosa para la salud, para hacer o estar con amigos y por aprender.

Por otro lado, podemos observar como la gran mayoría de nuestros alumnos presentan escasos motivos o ningunos por lo que no les guste la actividad física. Los pocos motivos que exponen son principalmente porque se cansan, porque se lesionan y porque sudan. 
Esto nos indica que la balanza de este grupo de alumnos se inclina de forma clara hacia la zona de me gusta la actividad física. Si a todos los pesos positivos le sumamos los negativos, nos sale un valor total de +269 .

Con estos datos, podemos sospechar que nuestros alumnos son bastante activos y que con las indicaciones y tareas del programa Perseo podemos reforzar esta actividad.

\section{ACTIVIDAD 7¿Qué puedo hacer para superar obstáculos?}

El objetivo de esta actividad es hacer reflexionar a los alumnos y alumnas sobre las barreras y obstáculos más comunes que pueden encontrar para ser o mantenerse activos, intentando encontrar posibles estrategias para evitarlos. De este modo, obtendrán recursos que les ayuden a llevar un estilo de vida más activo.

\section{Análisis de los datos}

A continuación, vamos a hacer un análisis de las distintas soluciones que nuestros alumnos han dado a los diversos problemas u obstáculos que se les presentan. Para ello, iremos haciendo un recuento y análisis de los diferentes ítems que arriba se presentan.

1. No tengo tiempo: las respuestas que más se dan son las de organizarme, hacer hueco y quitar otras actividades.

2. No tengo sitio: Recoger las cosas que estén por el medio (ordenar) ir a otro sitio adecuado (parque, pista, sitio amplio).

3. Nadie me acompaña: Hacer nuevos amigos, hacerlo sólo y hacerlo con la familia.

4. Me canso: descansar cada cierto tiempo, beber agua, ir a tu ritmo y hacer juegos que no te cansen.

5. Hace mal tiempo: Ir a un polideportivo o espacio cerrado, jugar en casa, jugar en casa de un amigo y esperar a otro día.

6. No tengo dinero: lo pido, me hago mi propio material, compro material barato, ahorrar, juego sin material, juego con el material que ya tengo.

Como podemos observar, las diferentes respuestas que nos dan los alumnos de este grupo en cada una de los ítems son bastantes lógicas y acertadas, por lo que podemos pensar, que han comprendido e interiorizado los objetivos que perseguía esta actividad perfectamente. 
Además, puedo verificar que esto es así, puesto que en la siguiente sesión estuvimos haciendo reflexiones sobre esta actividad y todos llegaron a la conclusión de que el niño/a que no practica deporte o actividad física es porque no quiere, ya que ante los posibles problemas, se pueden buscar multitud de soluciones.

\section{ACTIVIDAD 8: LA PIRÁMIDE DE LA ACTIVIDAD FÍSICA.}

El objetivo de esta actividad es producir un aprendizaje sencillo de ciertas recomendaciones sobre actividad física a través de dos herramientas: "La Pirámide de Actividad Física" y un "Decálogo para recordar".

\section{Análisis de los datos}

Al igual que en la actividad anterior, iremos analizando las respuestas de nuestros alumnos en cada uno de los ítems marcados en la tarea, nombrando las respuestas que más se han dado.

1. Actividades físicas de la vida diaria: andar, subir y bajar escaleras y correr.

2. Actividades físicas de resistencia: Correr, carretilla, comba, baloncesto y fútbol.

3. Actividades físicas de flexibilidad: pídola, volteretas, pino puente, twister y estiramientos.

4. Actividades físicas de fuerza: hacer pesas, la carretilla, pelea de gallos

5. Actividades sedentarias: televisión, ordenador y videoconsolas.

Vemos como en las actividades de resistencia, algunos alumnos han optado por poner diferentes juegos que hicimos en la $2^{2}$ sesión de condición física, lo que significa que nuestros alumnos comprendieron que actividades eran de resistencia, y otros alumnos que optan por ciertos deportes como lo son el fútbol y el baloncesto. Deportes que, como iremos viendo en las siguientes actividades, son los dos más practicados por este grupo de alumnos. Ocurre igual en las actividades de flexibilidad y de fuerza, donde un buen porcentaje de alumnos elige actividades y juegos que hicimos durante esta sesión de condición física.

Tanto en las actividades físicas de la vida diaria como en las actividades sedentarias, nuestros alumnos optan por respuestas evidentes y que ya las han ido aprendiendo a lo largo de las distintas actividades que han ido realizando. 


\section{ACTIVIDAD 9: ¿QUÉ VAS A PEDIR PARA TU CUMPLEAÑOS?}

El objetivo de esta actividad es triple. En primer lugar, enseñar a los alumnos y alumnas que hay juguetes que promueven la actividad física y otros que no. En segundo lugar, intentar incentivar a alumnos y alumnas a pedir como regalos juguetes que faciliten la práctica de actividad física. En tercer lugar, hacerles conscientes de que los juguetes inactivos deben de ser usados con moderación.

\section{Análisis de los datos}

Siguiendo la misma dinámica que en los análisis anteriores, vamos a analizar esta actividad diciendo las respuestas que más se repiten en cada uno de los apartados haciendo después un análisis final.

1. Materiales activos: pelotas, comba, patines, bicicleta, raquetas y canastas.

2. Materiales sedentarios: Televisión, ordenadores, móviles y diferentes tipos de videoconsolas.

Como podemos observar, nuestros alumnos tienen prácticamente el mismo número de materiales sedentarios que de materiales activos, lo que no podemos averiguar en este análisis es qué tipo de material es el que más utilizan. Sorprendentemente, dentro de los materiales inactivos, hay niños que tienen diferentes tipos de videojuegos, lo que nos alienta a pensar que les gustan bastante jugar a ellos, y esto significa que pasa mucho tiempo haciendo actividades sedentarias.

Curiosamente hay niños que colocan a la Wii dentro de los materiales activos y otros la colocan dentro de los materiales inactivos. Este es un debate que tuvimos en una de nuestras sesiones, donde los alumnos/as, guiados por mis preguntas, estuvieron debatiendo sobre si la Wii era activa o sedentaria. Yo les hacía preguntas tipo ¿Es igual de saludable jugar con nuestros amigos en la calle a un juego o deporte que hacerlo en casa jugando a la Wii? Hubo muchos niños que no encontraban ninguna diferencia, sin embargo hubo una niña que dio pie a otras discusiones. Esta niña dijo que no era igual de saludable, puesto que no estabas en contacto con otros compañeros, no compartías cosas con ellos. A lo que hubo niños que respondieron que podías quedar con amigos para jugar en casa con la Wii, por lo que si que te podías relacionar de la misma forma. Al final no llegamos a ninguna conclusión, puesto que esto es un debate de una gran índole, donde incluso profesionales de la materia no se ponen de acuerdo y los niños/as siguieron manteniendo sus posturas hasta el final. 


\section{ACTIVIDAD 10: ¿CÓMO SON TUS AMIGOS Y AMIGAS?}

El objetivo de esta actividad es que cada niño o niña conozca qué actividades físicas hacen sus mejores amigos y qué actividades físicas podrían realizar con ellos.

\section{Análisis de los datos}

En esta actividad, podemos comprobar que los amigos de nuestros alumnos practican una gran diversidad de actividad física, aunque en la mayoría de los casos se repiten. Las actividades que practican y que podrían practicar con sus amigos que más éxitos tienen son el fútbol, baloncesto, bicicleta, patines, natación y tenis.

En el apartado donde se les pregunta qué tipo de actividad física podrían practicar con ellos, he observado la influencia que algunos de los juegos y actividades propuestas durante mis sesiones han tenido, puesto que introducen algunos juegos populares como "Matar", el pañuelito, el pilla pilla etc.

En lo que respecta al apartado de con quien puedo practicar actividad física, hay unanimidad por parte del alumnado, pues casi el 100\% dicen con amigos y familiares. Además de los amigos y familiares, bastantes alumnos añaden a sus vecinos.

\section{ACTIVIDAD 11: OPORTUNIDADES PARA AUMENTAR MI ACTIVIDAD FÍSICA.}

El objetivo de esta actividad es enseñar a niños y niñas (y a sus familias) que una de las formas más fáciles de incrementar el nivel de actividad física es a través de las tareas que tenemos que realizar cada día.

\section{Análisis de lo datos}

Para una mayor comprensión de los datos obtenidos en esta actividad, iremos analizando los resultados por ítems. En el primero de ellos, que hace referencia al hecho de caminar al menos 2 veces a la semana durante 15 minutos, 10 alumnos (50\%) lo hacen entre 5 y 7 veces a la semana, 8 (45\%) alumnos caminan entre 2 y 4 veces a la semana más de 15 minutos y solamente 1 alumno (5\%) lo hace menos de dos veces a la semana. Datos que nos confirman que en lo que respecta a la actividad de andar, nuestros alumnos, concretamente un (95\%) lo hacen eventualmente y bastantes más veces a la semana del mínimo recomendado para su edad.

En lo que respecta a los padres, 19 padres y madres (47.5\%) caminan a la semana entre 5 y 7 días. 17 (42. 5\%) lo hacen entre 2 y 4 días y solamente $4(10 \%)$ lo hacen menos de 2 días a la semana. Porcentajes que nos indican que los padres caminan más o menos los mismos días a la semana que sus hijos. 
En Lo que respecta a ayudar en las tareas de la casa, evidentemente el porcentaje de los niños baja, solamente 7 (35\%) lo hacen entre 5 y 7 días. $10(50 \%)$ lo hacen entre 2 y 4 días y 3 (15\%) menos de 2 días. En esta actividad, los padres y madres, lógicamente se muestran más activos, y dentro de éstos, las madres realizan tareas del hogar más veces a la semana.

En lo que se refiere a nietros alumnos, el sexo no influye en su implicación en estas tareas, pues participan de la misma forma chicos y chicas.

En el siguiente ítems, que se refiere al número de días que se practica actividad física en el recreo, 18 alumnos (el 90\%) dicen practicar todos los días algún tipo de actividad física frente a 2 alumnos (10\%) que no la practican todos los días posibles. Llama la atención en este caso, una alumna que dice no practicar actividad física ningún día de la semana en el recreo.

La última actividad, que es de subir y bajar escaleras, podemos observar como 17 alumnos (85\%) las suben y bajan entre 5 y 7 días a la semana, es más, la gran mayoría las suben y bajan todos los días de la semana. Solamente 3 alumnos (15\%) dicen hacerlo menos de 5 días a la semana.

Si analizamos a los padres y madres 36 (90\%) suben y bajan escaleras entre 5 y 7 días a la semana y solamente $4(10 \%)$ lo hacen menos de 4 días a la semana.

Si hacemos una comparación entre los porcentajes obtenidos de los niños y los obtenidos de los padres, se corresponden unos con otros. Esto quiere decir que, si los niños ven que sus padres suben por las escaleras, ellos también lo hacen, o que no queda otro remedio que subirlas y por ello los porcentajes son prácticamente idénticos. Es más, en el $80 \%$ de los casos, los niños y padres suben a la semana el mismo número de veces por las escaleras, esto nos puede lleva a pensar que no les queda otro remedio que subirlas.

Por otro lado, el porcentaje que lo hace muy pocas veces o ninguna, no sabemos si es porque no tienen escaleras en sus domicilios.

\section{ACTIVIDAD 12: OPORTUNIDADES PARA AUMENTAR MI ACTIVIDAD FÍSICA. VOY A CONOCER MI BARRIO.}

EI OBJETIVO de esta actividad es descubrir las oportunidades para ser activo que existen en el barrio en el que cada alumno o alumna vive, y las actividades físicas que podría practicar si decidiese serlo. Además, trata de involucrar a las familias en esta 
pequeña tarea, invitándoles a pensar qué actividades podrían hacer también en el barrio si decidiesen ser más activos.

\section{Análisis de lo datos}

En esta actividad donde nuestros alumnos, tal y como hemos explicado anteriormente, tienen que organizar un circuito de actividad física tanto para ellos mismos, como para sus padres, podemos señalar que las actividades físicas y deportivas que más aparecen en el circuito de nuestros propios alumnos son el fútbol, baloncesto, nadar, bicicleta, patines, jugar y correr.

En el circuito de actividad física de mamá, las actividades que más se repiten son, tareas del hogar, andar, nadar, trabajar, gimnasia y sacar al perro a pasear.

En cuanto al circuito de los padres, las tareas más destacadas son correr, gimnasio, Tareas del hogar, trabajar y nadar.

\section{ACTIVIDAD 13: SE ACERCAN LAS VACACIONES}

El OBJETIVO de esta actividad es estimular que niños y niñas sigan siendo activos durante el verano.

Para ello, se les pedirá que evalúen cómo de confiados están en que serán activos durante el verano, y que se propongan diferentes actividades físicas para realizar en los meses de Julio y Agosto, adquiriendo el compromiso de realizarlas.

\section{Análisis de los datos}

Para el análisis del apartado donde se pregunta ¿Qué te gustaría hacer este verano? Vamos a nombrar las actividades físicas que más se repiten acompañadas del porcentaje de niños que las nombran.

El baloncesto lo nombran en un $60 \%$ de los casos, natación en otro $60 \%$, el fútbol lo nombran el $50 \%$ de los niños/as, bicicleta en otro $50 \%$ y por último, los patines en un $40 \%$.

En cuanto a la pregunta de ¿Qué AF te gusta en especial? Nadar y actividades acuáticas representan el $35 \%$ del total, el fútbol representa el $10 \%$, el baloncesto el $10 \%$, bicicleta otro $10 \%$, patinar un $15 \%$ y actividades como hípica, correr, vóley y pasear que representan un $5 \%$ cada una de ellas.

\subsection{DIARIO DEL PROFESOR}

Hemos de recordar que en el diario del profesor se han ido redactando las diferentes percepciones obtenidas en el desarrollo de todas las actividades y sesiones, así como 
las reflexiones que hacían nuestros alumnos al final de las mismas, que son las que nos indicaban si nuestros alumnos habían adquirido los aprendizajes que se estaban persiguiendo con el desarrollo de las mismas.

Los aspectos y conclusiones más destacadas de este diario son las siguientes:

En líneas generales, hemos podido constatar que los alumnos iban tomando conciencia de la importancia de la actividad física para conservar una buena salud. Todos ellos aprendieron a lo largo de las diferentes sesiones la variedad de oportunidades que tenemos para realizar actividad física en nuestro día a día. Además tomaron conciencia de que la actividad física no se centra solamente en los deportes reglados y que si nos paramos a pensar, podemos estar haciendo actividad física incluso en el hogar.

Todos nuestros alumnos diferenciaron desde un principio las actividades activas de las sedentarias así como los materiales activos y sedentarios.

Durante las sesiones, nuestros alumnos se mostraban alegres, motivados y participativos en la realización de las diferentes actividades propuestas.

En las actividades en las que había que salir del centro como la ruta en bicicleta y juegos de orientación, tanto los familiares como el equipo directivo del centro nos dieron todo su apoyo y colaboración. Lo que demuestra la filosofía del centro y la conciencia por parte de los padres de nuestros alumnos de la importancia de este tipo de actividades.

En lo que se refiere a las distintas reflexiones hechas al final de cada sesión, nuestros alumnos nos demostraban una y otra vez que habían asimilado los contenidos trabajados en cada una de ellas llegando incluso a sorprendernos ante la gran diversidad de opiniones y profundidad de algunas reflexiones personales. Lo que nos demostraba que se iban alcanzando los objetivos propuestos tanto de la Unidad Didáctica como los del programa Perseo.

El único Inconveniente que encontramos durante la aplicación de nuestro proyecto fue el tiempo que se perdía a la hora de explicar las fichas de Perseo, tiempo, que en parte pensamos que se veía recompensado por los aprendizajes que nuestros alumnos obtenían realizando estas actividades.

\subsection{CUESTIONARIO EVALUACIÓN FINAL ALUMNOS}

Es importante recordar que lo pasamos al finalizar la Unidad Didáctica. En el se hicieron preguntas relacionadas con los contenidos trabajados en la misma, así como preguntas relacionadas con una evaluación del material curricular de Perseo por parte 
de nuestro alumnado. Las respuestas de nuestros alumnos a cada una de estas fichas se pueden observar en el apartado de anexos, punto 8.4.

A continuación vamos a hacer un breve análisis de los datos recogidos en cada una de las preguntas:

\subsubsection{Análisis de datos.}

\section{1. ¿Qué os ha gustado más?}

Para analizar las respuestas de los alumnos/as ante la pregunta de ¿Qué os ha gustado más?, nos ha parecido adecuado decir las respuestas más repetidas acompañadas de su correspondiente \%.

Así la salida en bicicleta es lo que más ha gustado a 12 alumnos (50\%), los patines a 2 alumnos (8.3\%), Balonmano a otros dos (8.3\%), los juegos populares a 4 alumnos $(16.8 \%)$, los juegos de orientación a un (4.2\%) y los alumnos que han dado más de una respuesta o han dicho que todo son 5 y representan el $20.8 \%$ del total.

\section{2. ¿Qué os ha gustado menos?}

Para analizar la pregunta ¿Qué os ha gustado menos? Vamos a seguir la misma dinámica que en la pregunta anterior.

Ante esta pregunta , 8 alumnos ( $33.3 \%$ ) dicen que lo que menos les ha gustado hacer durante la Unidad Didáctica son las fichas del Programa Perseo, 10 alumnos (41.7\%) aseguran haberle gustado todo lo que hemos hecho, un solo alumno (4.16\%) del total responde no haber hecho deportes, otro la sesión de patines $(4.16 \%)$, otro alumno dice que el juego de la carretilla que representa otro (4.16\%) del total, otro alumno dice que la sesión de balonmano (4.16\%) y otro alumno dice que lo que menos le ha gustado es el no haber tenido más tiempo para hacer los juegos que llevaba preparados, que representa otro $(4.16 \%)$ del total.

\section{3. ¿Qué habéis aprendido?}

Analizando los resultados de esta pregunta, podemos observar como la mitad de los alumnos, es decir el $50 \%$ dicen haber aprendido que la actividad física es buena y saludable para su organismo, 9 (37.5\%) alumnos dicen que haber aprendido que la actividad física es divertida y pueden hacer amigos. Un alumno da una respuesta muy interesante diciendo que ha aprendido que la actividad física no es sólo deporte. Las demás respuestas van encaminadas a que han aprendido muchas cosas o muchos juegos y solamente un alumno, que representa el $4.16 \%$ del total, dice no haber aprendido nada. 
Si analizamos los porcentaje, podemos estar satisfechos con los mismos ya que se puede comprobar como los principales objetivos de esta UD y del Programa Perseo se han cumplido con creces, ya que nuestros alumnos se han concienciado de que practicar actividad física es bueno para nuestra salud, que es divertido y que comparto experiencias y momentos con mis amigos etc. Por lo que podemos llegar a pensar que lo van a tener en cuenta a la hora de organizar las actividades de su tiempo libre, reduciendo así las actividades sedentarias y por lo tanto, el riego de padecer obesidad.

\section{4. ¿Cómo valoráis las sesiones realizadas?}

Observando las respuestas que nuestros alumnos han dado ante la pregunta ¿Cómo valoráis las sesiones realizadas? Podemos decir que el $100 \%$ de los alumnos la valoran como muy bien o positivamente. Esto nos alaga, pues son ellos los que han participado en nuestras sesiones y actividades y evidentemente si todos las valoran positivamente podemos estar satisfechos con una gran parte de nuestro trabajo.

\section{5. ¿Qué os han parecido las fichas? ¿Habéis aprendido algo?}

12 alumnos (50\%) dicen haberle parecido un poco o bastante aburridas, sin embargo dicen haber aprendido bastante o mucho con ellas. El otro $50 \%$ dice que las fichas les han parecido bien, educativas y que han aprendido mucho con ellas. Solamente un alumno dice no haber aprendido nada con ellas.

Si el $99 \%$ de los alumnos dice haber aprendido haciendo estas fichas, podemos decir que las fichas del programa Perseo son educativas y que funcionan a la hora de enseñar a los alumnos los contenidos que se pretenden, alcanzando de este modo los objetivos marcados sobre el desarrollo de las mismas.

Una gran parte de nuestros alumnos hace hincapié en que aunque hayan aprendido cosas, consideran que se pierde bastante tiempo para explicarlas y hacerlas, restando tiempo a la clase práctica de Educación Física. Aspecto negativo, en el que estamos de acuerdo y que hemos podido observar en el desarrollo de nuestras sesiones, aunque consideramos que el tiempo que se pierde en la explicación de estas fichas, se recompensa con el nivel de aprendizaje adquirido por nuestros alumnos en aspectos relacionados con los beneficios de la práctica de actividad física.

\section{6. ¿Pensáis poner en práctica algunos juegos y actividades vistos en la U.D con vuestros amigos y familiares?}

Ante esta pregunta, el 99\% de los alumnos dice que piensa poner en práctica algunas actividades vistas a lo largo de la Unidad Didáctica con sus amigos y familiares. Respuestas que evidencian que las diferentes actividades llevadas a cabo durante 
nuestras sesiones les han gustado y que han comprendido la importancia y aplicación que tienen fuera del horario escolar.

\section{7. ¿Qué conclusiones o ideas generales sacáis de esta U.D?}

Más del $90 \%$ de las conclusiones o ideas generales que nuestros alumnos sacan de esta UUDD van encaminadas a que practicar actividad física con amigos y familiares es sano y divertido y que el sedentarismo no es bueno para la salud. Una prueba más de que se han alcanzado uno de los principales objetivos que se pretendían con el desarrollo de nuestra Unidad Didáctica.

\subsection{ENTREVISTA TUTOR DE PRÁCTICAS. DAFO}

En el cuadro que se presenta a continuación, podemos observar de una manera clara y concreta las fortalezas y debilidades tanto de la Unidad Didáctica como del Perseo. Para ello, hemos hecho un D.A.F.O. de la entrevista final que hicimos a mi tutor de prácticas. Si echamos un breve vistazo al cuadro, podemos observar como son más las fortalezas y oportunidades que se dan que debilidades y amenazas.

La entrevista y objetivos de la misma los podemos observar en el apartado de anexos, punto 8.5.

\begin{tabular}{|c|c|c|c|}
\hline $\begin{array}{l}\text { D } \\
\text { E } \\
\text { B } \\
\text { I } \\
\text { L } \\
\text { I } \\
\text { D } \\
\text { A } \\
\text { D } \\
\text { E } \\
\text { S }\end{array}$ & $\begin{array}{l}\text { D1.-- } \\
\text { D2.- } \\
\text { D3.- } \\
\text { D4.- } \\
\text { D5.- } \\
\text { D6.- }\end{array}$ & $\begin{array}{l}\text { F1.-Las sesiones planteadas aseguran diversión } \\
\text { y alternativas para su tiempo libre y de ocio. } \\
\text { F2.-Las tareas planteadas se desarrollan de } \\
\text { manera lúdica. } \\
\text { F3.- En el desarrollo de la UD se observa un } \\
\text { cambio en la motivación del alumnado. } \\
\text { F4.- La reflexión antes y después en el } \\
\text { planteamiento de las sesiones aplicadas al } \\
\text { programa Perseo. }\end{array}$ & $\begin{array}{c}\text { F } \\
\text { O } \\
\text { R } \\
\text { T } \\
\text { A } \\
\text { L } \\
\text { E } \\
\mathbf{Z} \\
\text { A } \\
\text { S }\end{array}$ \\
\hline $\begin{array}{l}A \\
M \\
E \\
N \\
A \\
Z \\
A \\
S\end{array}$ & $\begin{array}{l}\text { A1:- Corto tiempo de aplicación de la Unidad } \\
\text { Didáctica. } \\
\text { A2:- Al inicio los materiales curriculares crean } \\
\text { discrepancia entre el alumnado. }\end{array}$ & $\begin{array}{l}\text { O1:- Los juegos de las sesiones están calando en } \\
\text { los niños/as y cada vez más lo llevan a su tercer } \\
\text { tiempo pedagógico. } \\
\text { O2.- Los materiales curriculares fueron al final un } \\
\text { elemento motivador para conseguir los objetivos } \\
\text { que se pretendían }\end{array}$ & $\begin{array}{l}\text { O } \\
\text { P } \\
\text { O } \\
\text { R } \\
T \\
U \\
N \\
\text { I } \\
\text { D } \\
\text { A }\end{array}$ \\
\hline
\end{tabular}

\subsection{ANÁLISIS GLOBAL DE LOS RESULTADOS}


Creemos que es conveniente establecer este apartado donde se haga un análisis global de los resultados obtenidos, así como algunas percepciones personales obtenidas durante el desarrollo del mismo.

En general, podemos decir que la gran mayoría de los alumnos (68.18\%) se inclinan por practicar una mayor cantidad de actividades activas frente a las sedentarias. Son alumnos que suelen practicar bastante actividad física en su tiempo de ocio y se encuentran dentro de los parámetros normales que marca el programa Perseo. A esto hay que añadirle, que un gran porcentaje de padres $(54.76 \%)$ suelen practicar actividad física habitualmente, lo que induce a pensar que en muchos casos las practican junto con sus hijos o animan con su actitud a que ellos las practiquen de forma autónoma.

Por otro lado, del análisis hecho de las fichas, se desprende que un gran porcentaje de nuestros alumnos es consciente de los beneficios que tiene la actividad física para nuestra salud, tanto a nivel social, físico, psíquico y motriz. Donde presentan más problemas es para asociar los beneficios de la actividad física a nivel anatómico.

Consultando los resultados obtenidos en otras fichas, podemos decir que las principales razones por las que a nuestros alumnos les gusta la actividad física son porque se divierten, porque es beneficiosa para la salud, para hacer o estar con amigos y por aprender.

En lo que se refiere a los obstáculos que nos podemos encontrar a la hora de practicar actividad física, una gran mayoría de los alumnos (80\%) han mostrado una gran capacidad para proponer distintas soluciones y poder así seguir practicando actividad física.

Por otro lado, se ha podido observar cómo tras la realización de las fichas del programa Perseo, nuestros alumnos son capaces de diferenciar perfectamente entre los distintos tipos de actividades activas y las sedentarias. En este sentido, es importante resaltar que la gran mayoría de alumnos tiene el mismo número de materiales activos como de sedentarios. Es imposible determinar mediante estas fichas cuales son los que utilizan más a menudo, lo que si podemos demostrar tras la aplicación de Perseo, es que ellos sí que son conscientes de cuál de ellos son beneficiosos y cuales son perjudiciales.

Además son capaces de establecer distintos tipos de ejercicios y actividades para trabajar cada una de las Capacidades Físicas Básicas, así como reconocer cual o cuales de ellas se está trabajando en cada momento.

Tras hacer este análisis global de los resultados obtenidos, es importante resaltar que el Programa Perseo está diseñado para que se aplique durante un año en los colegios de enseñanza Primaria y que, realmente nosotros, solamente hemos dispuesto de un 
mes para comprobar su funcionamiento. Por otro lado, este programa no solo se preocupa porque los alumnos practiquen actividad física de forma regular, sino que también de que tengan una alimentación saludable, y para ello se implica a las familias $y$ todo el entorno escolar.

Nosotros, hemos intentado aproximarnos en todo lo posible a los contenidos del programa, estableciendo las modificaciones oportunas ya que es muy complicado plasmar todas las ideas de Perseo en solo un mes. Por ello, hemos decidido centrarnos principalmente en crear una adherencia a la práctica de actividad física por parte de nuestros alumnos, ya que era imposible centrarse plenamente en la alimentación, puesto que para esto se requería de una extensa participación de los familiares y docentes del centro, y no disponíamos de tiempo material para hacerlo.

Otros de los inconvenientes que hemos encontrado a la hora de aplicar Perseo, es el tiempo que se pierde a la hora de explicar las diferentes fichas a nuestros alumnos, los cuales se mostraban impacientes por salir al patio cuanto antes. Nosotros éramos conscientes de que en parte, era comprensible su actitud. Sabemos del poco tiempo semanal que disponemos para impartir el área de Educación Física y pensamos que este tiempo hay que aprovecharlo al máximo para impartir contenidos de una manera práctica, ya que como su propio nombre indica, el área de Educación Física consiste en educar a través de actividades físicas y del movimiento.

Este es quizás el principal inconveniente que hemos encontrado a la hora de aplicar Perseo, ya que por mucha prisa que nos diésemos a la hora de explicar las fichas, como mínimo perdíamos 10 minutos. Si a estos 10 minutos le sumamos el viaje de ida y vuelta al patio, más llevar y recoger el material, nos quedaban 30 minutos escasos de tiempo real de práctica de actividad física.

Dentro de estas limitaciones, podemos decir que hemos observado algunos cambios significativos en nuestros alumnos tras la aplicación del programa. Tras un análisis exhaustivo de todas sus fichas y conclusiones finales, podemos decir que en un gran porcentaje de alumnos hemos observado y detectado un "cambio de chip" respecto a su forma de pensar sobre los grandes beneficios que tiene para la salud la actividad física, si se practica de forma regular, y de cómo quieren cambiar o han cambiado a lo largo del desarrollo de la Unidad Didáctica, algunas actividades sedentarias por otras más activas.

Si en un mes hemos podido observar ciertos cambios de actitud respecto a la práctica de actividad física saludable, pensamos que si este programa se aplicase durante todo el año, pudiendo incidir más en contenidos relacionados con la alimentación, los resultados deberían de ser muy positivos, tal y como indican las conclusiones 
descritas anteriormente sobre la puesta en práctica de Perseo en otros colegios públicos de nuestro país.

\section{CONCLUSIONES}

Para establecer las conclusiones vamos a ir contestando cada uno de los objetivos planteados:

\section{1.- Adaptar el programa Perseo a una UD en Primaria.}

Hemos creado una Unidad Didáctica desde el área de Educación Física destinada a alumnos de $3^{\circ}$ ciclo de primaria, concretamente a alumnos de $5^{\circ}$ curso. Hemos adaptado el material curricular y los contenidos que trabaja el programa Perseo a esta Unidad Didáctica.

El material curricular de Perseo consta de 13 fichas distribuidas a lo largo de todo un curso escolar. Nosotros hemos adaptado estas 13 fichas para desarrollarlas a lo largo de las 8 sesiones de la que consta nuestra Unidad Didáctica. La adaptación consistió en agrupar las 13 fichas de Perseo diseñadas para todo el curso a nuestras 8 sesiones. Para ello, se agruparon diferentes fichas en una y se cambiaron el orden de las mismas, puesto que fuimos agrupando estas fichas en función de los contenidos que íbamos a trabajar en cada sesión, de tal forma que hubiese una clara coherencia entre los contenidos trabajados en la sesión con los contenidos trabajados en las fichas de Perseo.

Es importante resaltar que la adaptación de este programa no ha supuesto ningún cambio en lo que respecta a los contenidos y objetivos que propone Perseo.

Esta adaptación resultó bastante costosa, ya que, como hemos dicho anteriormente, el programa Perseo viene diseñado para trabajarlo durante todo un curso escolar, y el hecho de intentar reducir todos los contenidos trabajados en ese curso a solamente un mes, nos supuso un trabajo duro y difícil. Además tuvimos que coordinar nuestras sesiones con las actividades que nos proponían estas fichas, teniendo en algunas ocasiones que modificar algunas actividades de las mismas. Esfuerzo que ha merecido la pena tal y como nos indican los resultados finales obtenidos en el apartado de análisis.

\section{2.- Aplicar la adaptación del programa Perseo en un colegio público a través de la asignatura de EF.}


Pensamos que el área de Educación Física es la más indicada entre todas las áreas curriculares para desarrollar los objetivos que persigue Perseo, sobretodo en hábitos de actividad física saludable.

Hemos de recordar que hemos adaptado los contenidos que trabaja Perseo al tiempo del que disponíamos para aplicar este programa, dejando atrás algunos contenidos fundamentales como es el de alimentación, centrándonos fundamentalmente en crear una adherencia a la práctica de diferentes actividades físicas para mantener un estilo de vida saludable.

Aun así, pensamos que se han conseguido muchos de los objetivos que persigue este programa, detectando tanto por parte de nosotros como de nuestro tutor, un cierto cambio de actitud y de forma de pensar de nuestros alumnos respecto a la importancia que tiene practicar actividad física diaria para tener una buena salud.

La adaptación de las fichas ha funcionado a la perfección. Tras un análisis de las mismas, hemos podido observar como nuestros alumnos han ido respondiendo tal y como se espera Perseo que lo hagan, Han demostrado tomar conciencia de las diferentes actividades que se pueden realizar, cuáles son sus beneficios, buscar soluciones a los diferentes problemas planteados etc.

Por otro lado, las sesiones han funcionado muy bien. Los alumnos se mostraban muy participativos y motivados en todas las actividades propuestas, mostrándonos siempre su satisfacción con las diferentes sesiones y actividades planteadas. En las reflexiones hechas al final de cada sesión, nuestros alumnos nos daban respuestas que nos aseguraban que se habían alcanzado los objetivos que pretendíamos en cada una de ellas, llegando incluso a sorprendernos en algunas ocasiones con la profundidad y madurez de las mismas.

Observando el punto 5 de este trabajo donde se hace un análisis exhaustivo de los resultados obtenidos en las diferentes fichas y entrevistas, podemos verificar que la aplicación de la Unidad Didáctica adaptada a Perseo ha tenido una repercusión positiva en nuestros alumnos.

\section{3.- Analizar la aplicación de la Unidad Didáctica y el programa Perseo mediante entrevistas, trabajos y cuestionarios de los agentes implicados en el proyecto.}

La información más relevante que hemos sacado de estos instrumentos es la siguiente: Una gran parte del total de los alumnos aseguran haberles gustado todo lo que hemos hecho durante el desarrollo de la Unidad Didáctica, valorando la experiencia que han tenido durante las sesiones como muy positiva.

Aunque la mayoría de ellos coinciden en que, lo que menos les ha gustado hacer son las fichas del Programa Perseo, pareciéndoles aburridas, sin embargo, dicen haber 
aprendido bastante o mucho con ellas. En este sentido, una gran parte de nuestros alumnos hace hincapié en que aunque hayan aprendido cosas con las fichas de Perseo, consideran que se pierde bastante tiempo para explicarlas y hacerlas, restando tiempo a la clase práctica de Educación Física, aunque consideran que perder este tiempo merece la pena, ya que se adquieren aprendizajes importantes.

Por ello, el material curricular de Perseo fue al final un elemento motivador para conseguir los objetivos que se pretendían. Por tanto, podemos decir que

Las fichas de Perseo son educativas y que funcionan a la hora de enseñar a los alumnos los contenidos que se pretenden, alcanzando de este modo los objetivos marcados sobre el desarrollo de las mismas.

Por otro lado, todos nuestros alumnos piensan poner en práctica algunas actividades vistas a lo largo de la Unidad Didáctica con sus amigos y familiares. Respuestas que evidencian que las diferentes actividades llevadas a cabo durante nuestras sesiones les han gustado y que han comprendido la importancia y aplicación que tienen fuera del horario escolar. Por todo ello, podemos decir que las conclusiones o ideas generales que nuestros alumnos sacan de esta UUDD, van encaminadas a que practicar actividad física con amigos y familiares es sano y divertido y que el sedentarismo no es bueno para la salud, cumpliéndose así uno de los objetivos principales de nuestro trabajo.

Tras el análisis de nuestro trabajo mediante diferentes instrumentos, podemos sacar en conclusión que las sesiones se han planteado de una manera lúdica asegurando de este modo la diversión y alternativas para el tiempo libre y de ocio de nuestros alumnos y que en el desarrollo de la UD se observa un cambio en la motivación del alumnado.

\section{BIBLIOGRAFÍA}

Armstrong, N. Y Sparkes A. (1993). Issues in Physical Education (pp. 123-138). Londres: Cassell.

Bar-or, O. (1987). A commentary or children and fitness: a public hearth perspective. Research Quarterly for Exercise and Sport, 58,304-307.

Carranza, M., Garriga H. y Llinás, M. (2011). Saltamos a la ciudad. Barcelona: Grao.

Casimiro, A, Delgado, M y Águila, C (2005): Actividad física, educación y salud. Monografías humanidades. Universidad de Almería.

Centro de estudios sociosanitarios (2012). Programa Movi.

Universidad Castilla la Mancha. Disponible en: http://www.movidavida.org/ (Acceso: 22/ 09/2012). 
Crawford, R. (1987). Cultural influences on prevention and the emergence of a new health consciousness. Understanding and Encouraging Self Protective Behaviours (pp. 95-113). Cambridge: Cambridge University Press.

Cureton, K.J. (1987). Commentary on "Children and fitness: a public health perspective". Research Quarteriy jor Exercise and Sport, 58, 315-320.

Delgado, M. y Tercedor P. (1998). Estrategias de intervención en Educación para la Salud desde la Educación Física. Barcelona. Inde

Devís, J. y Peiró, C. (1993). La actividad física y la promoción de la salud en niños-as y jóvenes: la escuela y la educación física. Revista de Psicología del Deporte. 4: 71-86.

Devís, J. Peiró, C. (1997). Nuevas perspectivas curriculares en educación física: la salud y los juegos modificados. Barcelona: Inde.

Devís, J. y Peiró, C. (2001). Fundamentos para la promoción de la actividad física relacionada con la salud. Alicante: Marfil, 295-321.

Devís, J. y Peiró, C. (2002). La salud en la Educación Física escolar: ¿qué es lo realmente importante? Tándem, 8, 73-83.

De Gregorio, A. (2002). La relación de confianza profesor-alumno, clave de la educación. Madrid: FAE.

En Movimiento (2012). Disponible en:http://www.enmovimiento.net (Acceso: 10/ 10/2012).

Fraile, A. (1996). (coord.). Actividad física y salud en la escuela. Junta de Castilla y León. Valladolid.

Fox, K.R. (1991). Motivating children for physical activity: towards a healthier future. Journal 01Physical Education, Recreation and Dance, 62, 34-38.

Ministerios de Educación y Ciencia y de Sanidad y Consumo (2012). Programa Perseo, come sano y muévete. Disponible en:

http://www.perseo.aesan.msssi.gob.es/ (Acceso: 04/ 05/2012).

Ministerio de Sanidad y Consumo (2005). Estrategia NAOS.

http://www.naos.aesan.msssi.gob.es/naos/estrategia/que es/(Acceso: 10/05/2012).

Monahan, T. (1987). 'Activity' as good exercise? The Physician and Sportsmedicine, $15,181-186$.

Organización Mundial de la Salud (2012). 
Disponible en: http://www.who.int/es/ (Acceso: 07/ 04/2012).

Pate, R. R., blair, S.; Drustine, L., Eddy, D.O., Hanson, P., Painter, P., Smith, K. y Wolfe, L. (1991). Guidelines for exercise testing and prescription, American College of Sports Medicine: Lea \& Fegiber.

Peiró, C. y Devís, J. (1992). Nuevas perspectivas curriculares en educación fisica: la salud y los juegos modificados (pp. 77-108). Barcelona: Inde.

Pérez Samaniego, V. Y Devis Devis, J. (2003). La promoción de la actividad física relacionada con la salud. La perspectiva de proceso y de resultado. Revista Internacional de Medicina y Ciencias de la Actividad Física y el Deporte vol. 3 (10) pp. 69-74.

Perseo (2012). Disponible en (http://www.perseo.aesan.msps.es). (Acceso: 13/06/2012).

Powell, K.E., Thompson, P.D., Casperson, C.]. Kendrick, J.S. (1987). Physical activity and the incidence of coronary heart disease. Annual Review o/Public Health, 8,253-87.

Rodriguez, P.L. (2007). Educación Física y salud en primaria. Hacia una educación corporal significativa y autónoma. Barcelona: inde.

Ruiz, F., García, A., Casimiro, A.J. (1999). Nuevos horizontes en la E.F. y el deporte escolar. IAD. Málaga 35-44.

Sánchez Bañuelos, F. (1992). Bases para una Didáctica de la Educación Física y el Deporte. Madrid: Gymnos.

Sánchez Bañuelos, F. (1996). La actividad física orientada hacia la salud. Madrid: Biblioteca Nueva.

Sánchez Bañuelos, F. (2003). Didáctica de la Educación Física. Madrid: Pearson Educación.

Santos, S. (2005). La Educación Física escolar ante el problema de la obesidad y el sobrepeso. Revista Internacional de Medicina y Ciencias de la Actividad Física y el Deporte vol. 5 (19) pp.179-199.

SERRA L, et AL. (1998-2000).obesidad infantil y juvenil en España. Resultados del estudio Enkid.MedClin (Barc) 2003;121(19):725-32.

Simons-Morton, B.G., O'Hara, N., Paree, G.S. (1987). Children and fitness: a public health perspective. Research Quarterly for Exercise and Sport, 58, 295-302. 
Thao-Salud (2008). La obesidad infantil hoy. Barcelona: Programa Thao. Disponible en: http://thaoweb.com/ Acceso: 18/08/2012.

Tinning, R. (1993) Physical education and the Sciences of Physical Activity and Sport: symbiotic or adversial knowledge fields? Conferencia invitada al Congreso Mundial de Ciencias de la Actividad Física y el Deporte. Granada. 85

Tirrel, K. E Israel, L. (1991). La inactividad física aumenta los factores de riesgo para la salud y la capacidad física (Declaración de posición de la Federación Internacional de Medicina del Deporte -FIMS). Boletín Femede, 12,2-3. 